\title{
How does the initial configuration of oceanic ridge segments affect their interaction? Insights from analogue models
}

\author{
Tatiana Tentler ${ }^{1}$ and Valerio Acocella ${ }^{2}$ \\ Received 20 December 2008; revised 30 May 2009; accepted 9 September 2009; published 12 January 2010.
}

[1] Oceanic ridge segments interact forming different types of structures, of which transform faults and overlapping spreading centers represent the most common endmembers. This study uses analogue models for testing the role of the initial configuration of the ridges on the geometry and kinematics of the resulting interaction zones. The models, run in a centrifuge, consist of a lighter silicone (LDS), rising within a denser silicone (HDS) below a brittle layer simulating the oceanic lithosphere. Precut fractures in the brittle layer simulate the initial configuration of oceanic ridges. The rise and lateral spreading of the LDS induce the propagation, widening, interaction, and linkage of the fractures. We varied the offset and overlap between the fractures, obtaining 10 distinctive types of interaction. Variations in fracture overlap and offset define several interaction types. Increase of fracture overlap leads to interaction zones of lower aspect ratio, with fractures propagating at lower angles to the mean extension direction. Increase of offset leads to the elongation of the interaction zones with the new fractures propagating subparallel to the extension direction. The comparison with several examples of natural ridges shows close geometric similarities, confirming the existence of predominant types of ridge interaction. Among these, ridges with smaller offsets develop interactions similar to overlapping spreading centers, whereas ridges with larger offsets have geometries reminiscent of transform zones. The comparison between experimental and natural examples suggests that the observed wide spectrum of ridge interaction types in nature results from the initial configuration of the divergent plate boundary.

Citation: Tentler, T., and V. Acocella (2010), How does the initial configuration of oceanic ridge segments affect their interaction? Insights from analogue models, J. Geophys. Res., 115, B01401, doi:10.1029/2008JB006269.

\section{Introduction}

[2] Mid-oceanic ridges (MORs) result from the coalescence of growing rift segments [Schouten et al., 1985; Macdonald et al., 1988, 1991]. During punctiform initiation of seafloor spreading, the focusing of the tectonic strain and/ or the rise of magma leads to development of isolated ridge segments [Bonatti, 1985]. The initial location of these protoridges depends upon the presence of weaker lithospheric portions; these may be both mechanically (as, for example, due to preexisting anisotropies) or thermally (as for example due to hot spot activity) weakened [e.g., Hayward and Ebinger, 1996]. Once localized, the growth of the protoridges is characterized by a feedback between regional extension and magmatism: (1) on the one side, extension causes decompression and magma generation and (2) on the other side, the rise of magma induces extension at the surface [e.g., Sigmundsson, 2006, and references therein]. Whatever the initial driving factor, once a ridge starts to develop, such a feedback may maintain its growth. This

\footnotetext{
${ }^{1}$ Department of Geology and Mineralogy, Royal Museum for Central Africa, Tervuren, Belgium.

${ }^{2}$ Dipartimento Scienze Geologiche, Universitá Roma Tre, Rome, Italy.

Copyright 2010 by the American Geophysical Union. 0148-0227/10/2008JB006269\$09.00
}

mechanism of formation implies that, at the beginning, oceanic ridges are not continuous and straight features; rather, the isolated ridge segments are characterized by variable overlap and offset values [Hayward and Ebinger, 1996, and references therein].

[3] The growth of ridge segments includes their alongstrike propagation, leading to the interaction of nearby ridges [Macdonald et al., 1988, 1991, 1992]. Such an interaction may be achieved through the progressive increase in the overlap between the segments and the development of a hook-shaped configuration, distinctive for overlapping spreading centers (OSC) [Macdonald and Fox, 1983; Macdonald et al., 1992]. Alternatively, the interaction may occur through the development of throughgoing fracture zones, with predominant strike-slip motions, at high angle with the direction of the interacting ridges, forming a transform fault (TF) [Macdonald et al., 1992]. Having distinct geometries, OSC and TF may be considered as end-member configurations of ridge interaction. While OSC are usually found at smaller scales (a few kilometers to a few hundred kilometers), TF are usually observed at larger scales (hundreds to thousands of kilometers [Macdonald, 1998]).

[4] Oceanic ridges, being submerged, can be seldom directly investigated, with the exception of the oceanic ridge of Iceland [Bjarnason et al., 1993; Gudmundsson, 
1995a; Bergerat et al., 1998]. Even though information may be obtained from geophysical data [Macdonald, 1998, and references therein], the difficulty of a direct access to submarine ridges hinders detailed investigation of ridge architecture and interaction. Therefore, there is a limited knowledge on the conditions controlling specific type of ridge interactions [Acocella et al., 2000; Dauteuil et al., 2002; Tentler, 2005; Tentler and Mazzoli, 2005], on the early stages of formation of TF [Bonatti, 1985; Bjarnason et al., 1993] and OSC [Macdonald et al., 1984; Gudmundsson and Brynjolfsson, 1993], as well as on their magmatic budget [Macdonald and Fox, 1983, 1988; Lonsdale, 1986; Mutter et al., 1988; Kent et al., 1993]. Also, many oceanic ridges, including East Pacific Rise (EPR) [Lonsdale, 1983, 1986], Mid-Atlantic Ridge (MAR) [Devey et al., 1994], and Southeast Indian Ridge [Small, 1998], interact developing hybrid and complex features, resulting in types of interaction zones being transitional between OSC and TF.

[5] Additional open questions to be investigated concern the relationships between interacting ridges and the formation of microplates. Early studies suggest that OSC configurations are a requisite for the development of microplates [Hey, 1977; Macdonald and Fox, 1983]. However, despite the increasingly comprehensive mapping [e.g., Searle et al., 1989; Schouten et al., 1993], the initiation and evolution of microplates are still poorly understood [Naar and Hey, 1991; Schouten et al., 1993] and there is no consensus on the processes leading from overlapping ridges to microplates [Neves et al., 2003; Katz et al., 2005].

[6] Various attempts have been made to model ridge segments. Spreading ridges were simulated by means of extensional fractures propagating in pulled apart paraffinwax plates, observing variations in length, orientation and overlap of the ridge segments [Oldenburg and Brune, 1972]. Analogue models have been widely used to investigate the development of TF [Mauduit and Dauteuil, 1996; Magde et al., 1996], as well as the propagation and linkage of MORs under orthogonal to highly oblique extension [Dauteuil and Brun, 1993; Benes and Scott, 1996; Thibaud et al., 1999; Mart and Dauteuil, 2000; Tentler, 2003a, 2003b]. Shemenda and Grocholsky [1991, 1994] proposed that different types of ridge interactions arise from variations in crustal strength and magmatic supply. Modeling of Tentler [2007] emphasized differences in ridge segmentation, depending on whether failure along the ridge axis develops in localized or diffused fashion. The control of the initial configuration of the ridges on their interaction and on the development of microplates have also been experimentally modeled [Shemenda and Grocholsky, 1991; Magde et al., 1996; Mauduit and Dauteuil, 1996; Tentler, 2003b; Dauteuil et al., 2002; Katz et al., 2005]. However, these studies commonly used mechanical anisotropies connecting the analogues of spreading centers, having no direct equivalent in nature, at least in the early interaction stages, where no preexisting mechanical or rheological anisotropy connected the rift segments. None of these studies had systematically evaluated the role of the initial configuration of the interacting ridges without preexisting anisotropies in between. Such a condition may be crucial in understanding whether the observed ridge interaction types result from their geometric setting or are related to other factors, such as the magmatic supply, thermal gradients or crustal thickness [e.g., Shemenda and Grocholsky, 1991, 1994].

[7] Here we present results of analogue modeling performed (1) to study how the initial configuration of spreading ridges affects their interaction; such an "initial configuration" is related to the birth stage of MORs, when isolated protoridges form where the lithosphere is weaker; (2) to define the parameters controlling the wide spectrum of observed interactions; and (3) to gain insights on the relationships between the initial geometry of the ridges and the development of microplates. The main difference of this study with regard to the previous experimental ones is the lack of a mechanical basal discontinuity connecting the spreading centers, at any evolutionary stage.

[8] A part of this experimental set was recently discussed in a study exclusively focused on specific imposed conditions (total length of the fractures versus their overstep), leading to the formation of end-member ridge interactions (OSC and TF [Acocella, 2008]). While these specific problems will not be addressed by the present study, the larger data set considered here consists of several tens of models. This larger data set allows distinguishing a significantly wider spectrum of ridge interactions, with transitions between OSC and TF, varying as a function of the imposed overlap (OL) and offset (S) conditions. These experiments are here discussed and qualitatively and semiquantitatively compared to natural examples, highlighting similarities and discrepancies.

\section{Experimental Apparatus, Scaling, and Materials}

[9] Models were deformed in a large capacity centrifuge [Ramberg, 1981]. Each model consisted of three material units (Figure 1a): (1) a parallelepiped of lower density silicone (LDS), simulating the asthenosphere, at the base of the model box; (2) a larger parallelepiped of higher density silicone (HDS), simulating the upper mantle within the asthenosphere; and (3) an uppermost brittle layer, simulating the oceanic lithosphere. The LDS unit was embedded within the HDS and two offset fractures were induced within the brittle layer before the experimental run in the centrifuge. The imposed variations in the OL and $\mathrm{S}$ values allowed the investigation of their controls on the development of different interaction types (Figure 1b). The use of the precut fractures is based on the possibility to describe the propagation and interaction of oceanic ridges using the crack growth theory, where a ridge segment is approximated by a mode I crack [e.g., Pollard and Aydin, 1984; Morgan and Parmentier, 1985]. The present experimental approach follows, except for the use of the precut fractures, the one used by Tentler [2003a, 2003b, 2007], and is the same as that adopted by Acocella [2008].

[10] Deformation within the model was induced by the centrifuge run, at $\sim 10^{2} \mathrm{~g}$. Due to the density contrast, the LDS rose within the HDS (Figures 1c and 1d), followed by its lateral spreading at the base of the brittle layer (Figure 1e). This spreading induced, in turn, stretching of the brittle layer and growth of the precut fractures. The growth was characterized by the along-strike propagation and subsequent interaction of the fractures. 

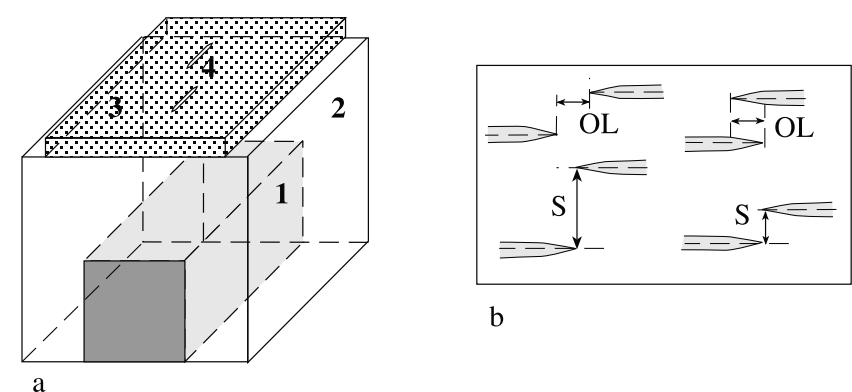

b
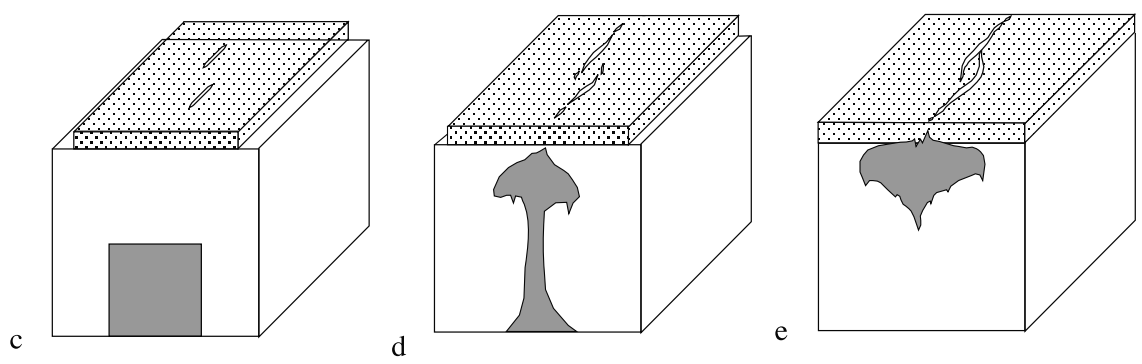

Figure 1. (a) Experimental setup: (1) as lower-density silicone (LDS), simulating the asthenosphere; (2) higher-density silicone (HDS), simulating the upper mantle; (3) the uppermost brittle layer, simulating the oceanic lithosphere; and (4) precut fractures. (b) Variation in the imposed fracture overlap (OL) and offset (S). (c-e) Progressive stages of deformation in the models in section view.

[11] Models were geometrically, kinematically and dynamically scaled [Ramberg, 1981] accordingly to the ratios shown in Table 1. A length ratio between model and nature was chosen as $\mathrm{Z}^{*}=10^{-7}$, with $1 \mathrm{~cm}$ in the model corresponding to $\sim 100 \mathrm{~km}$ in nature. The densities of the oceanic crust and upper mantle $\left(2600-2900 \mathrm{~kg} \mathrm{~m}^{-3}\right)$ and of the commercially available experimental materials (900$1800 \mathrm{~kg} \mathrm{~m}^{-3}$ ) imposed a density ratio of $\rho^{*} \sim 0.5$. Since the models were run at $\sim 10^{2} \mathrm{~g}$, the gravity ratio was $\mathrm{g}^{*}=$ $10^{2}$. As a result, the stress ratio between model and nature corresponds to $\sigma^{*}=\rho^{*} \mathrm{~g}^{*} \mathrm{z}^{*} \sim 5 \times 10^{-6}$. The rheology of the oceanic lithosphere was approximated considering an overall brittle behavior [Ranalli, 1995]. Its cohesion, having the dimensions of a stress, must be scaled at $\sim 5 \times 10^{-6}$; the mean cohesion for the rocks of $\mathrm{c} \sim 10^{7} \mathrm{~Pa}$ required a low cohesion analogue (c $\sim 50 \mathrm{~Pa})$. For this purpose, the oceanic lithosphere was simulated by a mixture of vaseline $(60 \%)$, paraffin $(20 \%)$ and gypsum powder $(20 \%)$, with a cohesion of very few hundreds of Pa. Similar mixtures have been previously used to model oceanic lithosphere in a centrifuge [Tentler, 2003a, 2003b].

[12] Newtonian silicone (LDS), with a density $\rho=$ $1310 \mathrm{~kg} / \mathrm{m}^{3}$ and viscosity $\mu \sim 3 \times 10^{4} \mathrm{~Pa} \mathrm{~s}$, represented a thermally anomalous asthenosphere, with a mean viscosity of $\mu \sim 10^{19} \mathrm{~Pa} \mathrm{~s}$ in nature [Ranalli, 1995]. The surrounding colder mantle, with a mean viscosity of $\mu=10^{20}-10^{21}$ [Ranalli, 1995], was simulated using a denser and more viscous silicone, adding painter's putty (HDS; $\mu=$ $\left.1410 \mathrm{~kg} / \mathrm{m}^{3} ; \mu \sim 7 \times 10^{5} \mathrm{~Pa} \mathrm{~s}\right)$. Thus, the density $\left(\sim 100 \mathrm{~kg} / \mathrm{m}^{3}\right)$ and viscosity $(\sim 50 \mathrm{~Pa} \mathrm{~s})$ contrast between the LDS and HDS simulated an average density and viscosity contrast between a hotter asthenosphere and the surrounding mantle.

[13] The thickness of LDS and HDS were $\sim 1$ and $\sim 2 \mathrm{~cm}$, respectively. Common strain rates related to the rise of asthenosphere in nature are in the order of $\varepsilon_{\mathrm{n}} \sim 10^{-15} \mathrm{~s}^{-1}$
[Ranalli, 1995] and those induced in the experiments are $\varepsilon_{\mathrm{m}} \sim 10^{-3} \mathrm{~s}^{-1}$, defining a strain rate ratio of $\varepsilon^{*}=10^{-12}$. As the time ratio between model and nature is $\mathrm{t}^{*}=1 / \varepsilon^{*} \sim 10^{12}$, $1 \mathrm{~s}$ in the experiments corresponds to $3.3 \times 10^{4}$ years in nature, and a common run of $\sim 5 \mathrm{~min}$ in the centrifuge simulated a time span of $\sim 10^{7}$ years.

[14] In our experiments, we did not consider the role of the spreading rate and the thermal profile of the ridges. The former will be subject for further research, whereas the latter constitutes the most notable limitation of any analogue modeling study. Both parameters are closely related, as the spreading rate influences the thermal profile of a ridge, as well as its rheology, possibly affecting also ridge interaction. For example, the development of OSCs and microplates occurs preferably at fast spreading ridges, while TFs are more common at slow spreading ridges [Macdonald, 1998; Thibaud et al., 1999; Cochran et al., 2003; Hey et al., 2004]. Despite these limitations, our experimental approach allows simulating the general and important features of ocean ridge interaction, using a wide range of initial configurations.

[15] The extent of applicability of the experimental results is limited by the knowledge of such natural parameters as viscosities, timescales and strain rates. The aim of the experiments is not to simulate a specific case, as the difficulty of determining its natural parameters would limit the applicability of the models. The goal is rather to understand the overall mechanism of interaction, which might be valid for a wide range of natural cases.

\section{Results}

\subsection{General Evolution of Models}

[16] The experimental set consists of 34 experiments, in which the offset $\mathrm{S}$ and overlap OL (negative in underlapping and positive in overlapping configurations) between 
Table 1. Model Ratios Used for the Scaling of the Analogue Materials Employed in the Experiments

\begin{tabular}{ll}
\hline Parameter & Model/Nature Ratio \\
\hline Length & $\mathrm{L}^{*} \sim 10^{-7}$ \\
Density & $\rho^{*} \sim 0.5$ \\
Gravity & $\mathrm{g}^{*} \sim 10^{2}$ \\
Stress & $\sigma^{*} \sim 5 \times 10^{-6}$ \\
Viscosity & $\mu^{*} \sim 10^{-14}$ \\
Strain rates & $\varepsilon^{*} \sim 10^{-12}$ \\
Time & $\mathrm{t}^{*} \sim 10^{12}$ \\
\hline
\end{tabular}

interacting fractures were systematically varied (Figure $1 \mathrm{~b}$ and Table 2). As a result of the different initial configurations of fractures in the pairs, we obtained different modes of their interaction (Figures $2 \mathrm{a}-2 \mathrm{c}$ ).

[17] The general evolution of the models may be illustrated through a representative model, that adequately demonstrates the main features developed during fracture interaction (Figures $2 \mathrm{~d}-2 \mathrm{~g}$ ). The initial configuration of the two parallel fractures has $\mathrm{S}=0.5 \mathrm{~cm}$ and $\mathrm{OL}=0 \mathrm{~cm}$ (Figures $1 \mathrm{c}$ and $2 \mathrm{~d}$ ). In the undeformed stage, the LDS is embedded below the HDS and the precut fractures. A passive strain marker grid has been imprinted at the surface of the model. After $150 \mathrm{~s}$ of run in the centrifuge, the rise of the LDS at the base of the brittle layer (Figure 1d) leads to the along-strike propagation and widening of the fractures (Figure 2e). The propagation may occur by advancing fracture tips or developing isolated cracks ("daughters") forming ahead of the tips of the precut fractures ("parents"). Fracture propagation increases OL of the parents fractures, while the onset of the interaction is highlighted by their moderately diverging tips. The interaction zone is characterized by distributed strain, highlighted by the distorted markers on the reference grid (Figure 2e). After $\sim 240 \mathrm{~s}$, the fracture tips curve toward the opposite fracture, showing an overall arcuate shape (Figures $2 \mathrm{c}$ and $2 \mathrm{f}$ ). At this stage, the strain within the interaction zone focuses at the tips of the fractures and along their inner sides. Such an overlapping configuration, characterized by a significant degree of stretching $(\sim 80 \%)$, may be defined as an advanced stage of deformation. After $\sim 360 \mathrm{~s}$, the model reaches a stable or mature configuration, characterized by the complete rise of the LDS within the HDS, at the base of the brittle layer (Figure 1e). This stage shows further fracture widening and propagation, with one of the fractures reaching the other, thus starting the linkage (Figure $2 \mathrm{~g}$ ). Once a fracture reaches the other, further propagation of the less actively growing fracture is commonly inhibited. Therefore, any increase in the strain within the linkage area is usually related to the widening of the more active fracture.

[18] The incremental and finite strain has been estimated considering the eccentricity $(\mathrm{E})$ of the strain marker ellipses, calculated as the ratio between the length of the minor and major axes of the ellipse [Ramsay and Huber, 1987]. Each interval of the E magnitude is shown by a different shade of gray in Figures $2 \mathrm{~h}-2 \mathrm{j}$ with darkest shade corresponding to higher strain intensity. The direction of maximum stretching in Figure $2 \mathrm{k}$ is estimated considering the orientation of the elongation axis of the strain marker ellipses for each unit of the grid. During stages of the fracture propagation, incremental strain progressively increases toward the central portion of the overlap zone (Figures $2 \mathrm{~h}$ and $2 \mathrm{i}$ ). In the final experimental stage, the zone of fracture interaction is the most deformed domain, with a strain of at least 1.5-2 orders of magnitude larger than the surrounding areas (Figure 2j). The finite strain attains its maximum value nearby the tip of the most actively propagating (upper) fracture. Such a strain is mainly related to shearing, with a tendency for the stretching direction to become parallel to the nearest fracture (Figure $2 \mathrm{k}$ ). As a result, within the most strained zone, the stretching direction is highly oblique (at angles of $30^{\circ}-60^{\circ}$ ) to the extension direction of the model. Outside this zone, the strain intensity gradually decreases and the stretching direction becomes less defined.

[19] Variation in the tested values of S (from 5 to $12 \mathrm{~mm}$ ) and OL (from -9 to $6 \mathrm{~mm}$ ) resulted in 10 main modes of interaction, expressed through different values of the aspect ratio of interaction zone (A), the distance between the interacting fracture tips $(\mathrm{T})$, the length of the daughter fractures $(\mathrm{L})$, the propagation angle $(\alpha)$, the orientation of the major axis of the overlap zone $(\beta)$, and the curvature of the propagating fractures within it $(\delta$; Figure 3$)$. Data concerning the 10 types of interaction (Figure 3 ) are based on at least 2 experiments for each type (Table 2), characterizing early to advanced growth stages preceding fracture linkage. Characteristic initial configurations of interaction zones are expressed as a function of S and OL (Figure 3).

Table 2. Variation of the Main Geometric Parameters Imposed in the Initial Construction of the Models and Developed During the Fracture Interaction in the Experiments

\begin{tabular}{|c|c|c|c|c|c|c|}
\hline $\begin{array}{c}\text { Type of } \\
\text { Fracture } \\
\text { Interaction }\end{array}$ & $\begin{array}{c}\text { Fracture } \\
\text { Overlap }(\mathrm{mm})\end{array}$ & $\begin{array}{c}\text { Fracture } \\
\text { Offset } \\
(\mathrm{mm})\end{array}$ & $\begin{array}{c}\text { Aspect } \\
\text { Ratio A of } \\
\text { Overlap }\end{array}$ & $\begin{array}{c}\text { Angle } \alpha \text { of } \\
\text { Fracture } \\
\text { Propagation }\end{array}$ & $\begin{array}{c}\text { Elongation } \\
\text { Angle } \beta \text { of } \\
\text { Overlap Zone }\end{array}$ & $\begin{array}{c}\text { Fracture } \\
\text { Curvature } \delta\end{array}$ \\
\hline 1.1 & -7 to -9 & $5-7$ & $2-6$ & $3-10^{\circ}$ & $15-20^{\circ}$ & $0-5^{\circ}$ \\
\hline 1.2 & -4 to -7 & $5-7$ & $2.5-4$ & $20-25^{\circ}$ & $20-30^{\circ}$ & $0-10^{\circ}$ \\
\hline 1.3 & -1 to -4 & $5-7$ & $1.5-2$ & $25-30^{\circ}$ & $30-40^{\circ}$ & $20-45^{\circ}$ \\
\hline 1.4 & 0 & $5-7$ & $1-1.5$ & $20-30^{\circ}$ & $20-40^{\circ}$ & $20-40^{\circ}$ \\
\hline 1.5 & $1-4$ & $5-7$ & $1-2$ & $60-80^{\circ}$ & $50-60^{\circ}$ & $0-10^{\circ}$ \\
\hline 1.6 & $4-6$ & $5-7$ & $2-3.5$ & $45-55^{\circ}$ & $40-50^{\circ}$ & $10-25^{\circ}$ \\
\hline 2.1 & -4 to -7 & $10-12$ & $1.5-2$ & $40-50^{\circ}$ & $50-60^{\circ}$ & $10-25^{\circ}$ \\
\hline 2.2 & -1 to -4 & $10-12$ & $2-3$ & $45-70^{\circ}$ & $60-70^{\circ}$ & $5-15^{\circ}$ \\
\hline 2.3 & 0 & $10-12$ & $3-4$ & $65-80^{\circ}$ & $80-90^{\circ}$ & $0-10^{\circ}$ \\
\hline 2.4 & $1-4$ & $10-12$ & $1-2$ & $40-65^{\circ}$ & $60-70^{\circ}$ & $5-20^{\circ}$ \\
\hline
\end{tabular}



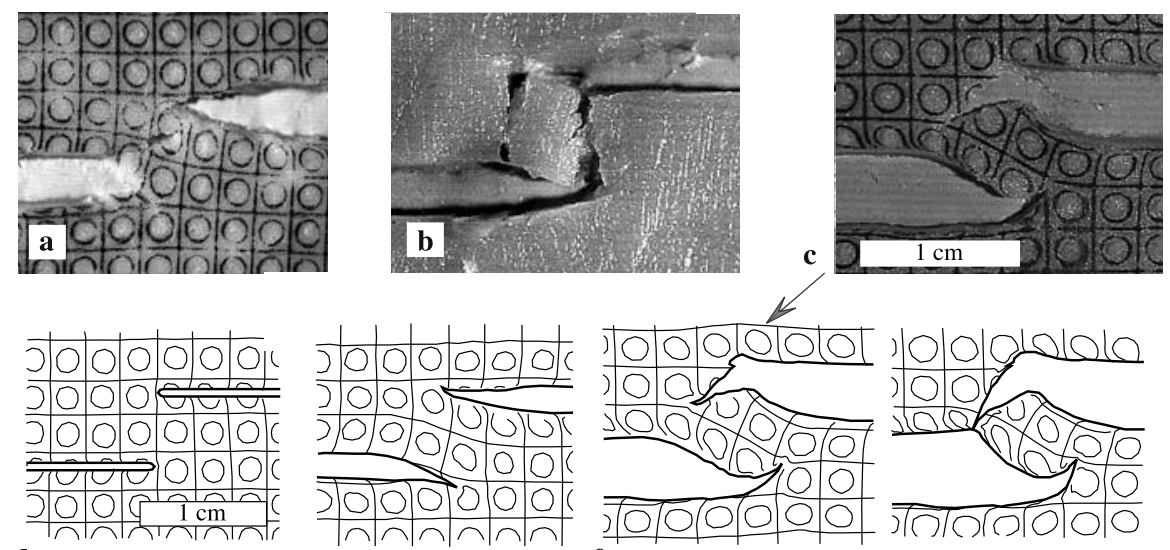

d
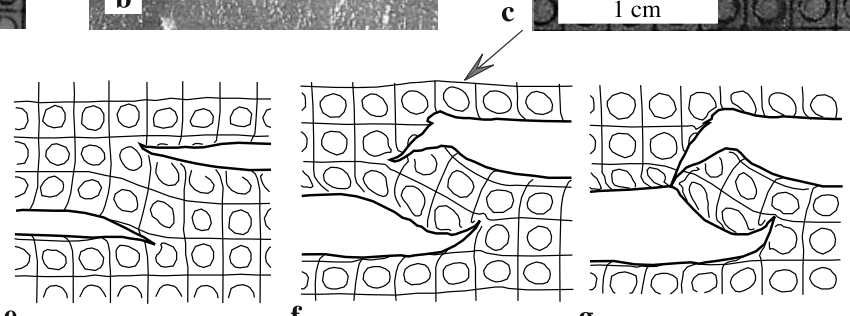

e

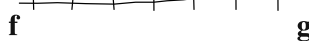

g
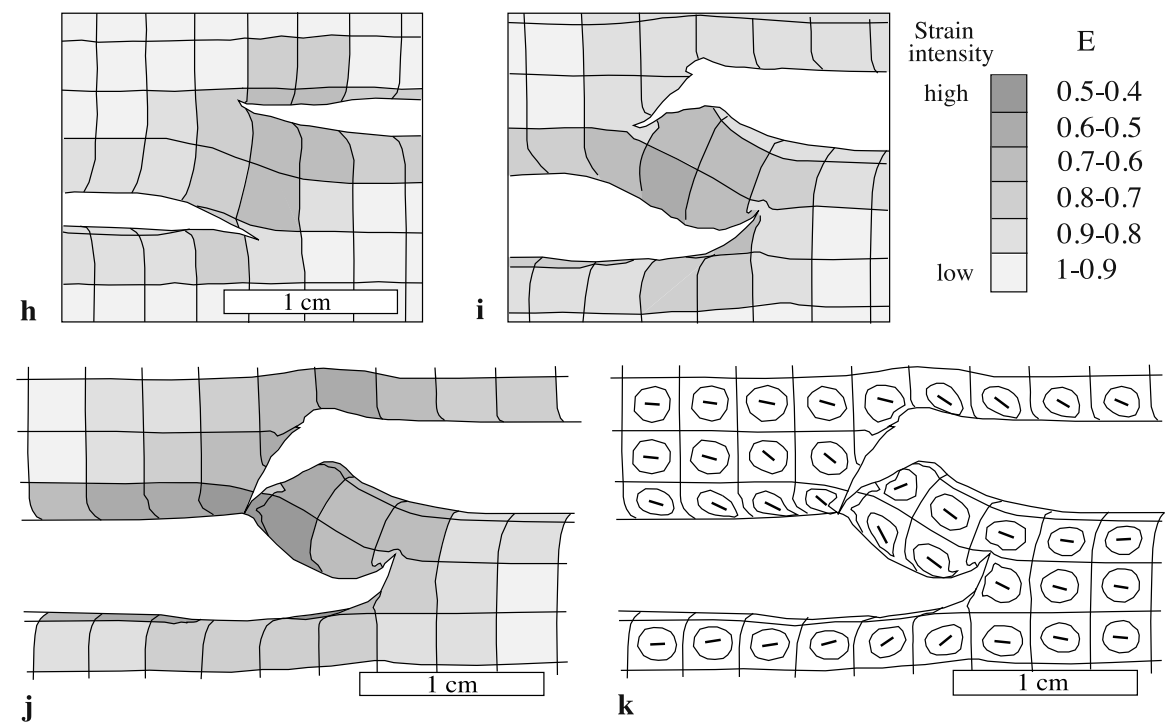

Figure 2. $(\mathrm{a}-\mathrm{c})$ Examples of different types of fracture interactions in a map view. $(\mathrm{d}-\mathrm{g})$ Evolution of the model with imprinted passive strain marker grid in a representative experiment. (h and i) Strain intensity for incremental and (j) final strain of the model estimated considering the eccentricity (E) of the strain marker ellipses calculated as the ratio between the length of the minor and major axes of the ellipse; each $\mathrm{E}$ interval is shown by a different shade of gray with progressively darker shade for correspondingly highest strain intensity. (k) Stretching direction in the final deformation stage estimated considering the orientation of the elongation axis of the strain marker ellipses for each unit of the grid.

\subsection{Types of Interaction as a Function of the Offset and Overlap}

[20] Considering a constant offset $5<\mathrm{S}<7 \mathrm{~mm}$ (lower values of S), six interaction types, from negative $(-9<\mathrm{OL}<$ $-7 \mathrm{~mm})$ to positive overlap $(\mathrm{OL}=4-6 \mathrm{~mm})$, are distinguished (Figure 3 ).

[21] In type 1.1, fractures with larger negative overlap $(-9<\mathrm{OL}<-7 \mathrm{~mm})$ interact by means of daughter fractures nucleating in the underlapping zone. These are straight $\left(0^{\circ}<\delta<5^{\circ}\right)$, subparallel to their parents $\left(3^{\circ}<\alpha<\right.$ $10^{\circ}$ ) and have a tendency to link with each other. The interaction zone has a large aspect ratio $(2<\mathrm{A}<5)$, and is elongated subparallel to the fractures $\left(15^{\circ}<\beta<20^{\circ}\right)$.

[22] In type 1.2, fractures with medium negative overlap $(-7<\mathrm{OL}<-4 \mathrm{~mm})$ usually interact through new isolated fractures, nucleated within the underlapping zone. These daughters are usually straight $\left(0^{\circ}<\delta<10^{\circ}\right)$ and oblique $\left(10^{\circ}<\alpha<25^{\circ}\right)$ to their parents. The daughters propagate toward the parents tips, eventually linking. Complete coalescence is seldom observed, so that the daughters commonly remain isolated. The interaction zone has a quite large aspect ratio $(2<\mathrm{A}<4)$ and is oblique with regard to the parent fractures $\left(20^{\circ}<\beta<30^{\circ}\right)$.

[23] In type 1.3, fractures with smaller negative overlap $(-4<\mathrm{OL}<-1 \mathrm{~mm})$ propagate obliquely $\left(25^{\circ}<\alpha<30^{\circ}\right)$ and curving while interacting. The tip of each fracture first propagates away (outward) from the interaction zone and then toward the other fracture (inward), developing curved fractures $\left(20^{\circ}<\delta<45^{\circ}\right)$. If linkage occurs, the area between the curved fracture tips becomes isolated and rotates. The interaction zone has a lower aspect ratio $(1.5<\mathrm{A}<2)$ and is highly oblique with regard to the parent fractures $\left(30^{\circ}<\beta<\right.$ $\left.40^{\circ}\right)$.

[24] In type 1.4, fractures with $\mathrm{OL}=0$ interact in a similar fashion to type 1.3 , but show larger variations in the propagation angle $\left(20^{\circ}<\alpha<30^{\circ}\right)$, resulting in a smaller aspect ratio of the interaction zone $(1<\mathrm{A}<2)$, oblique with 


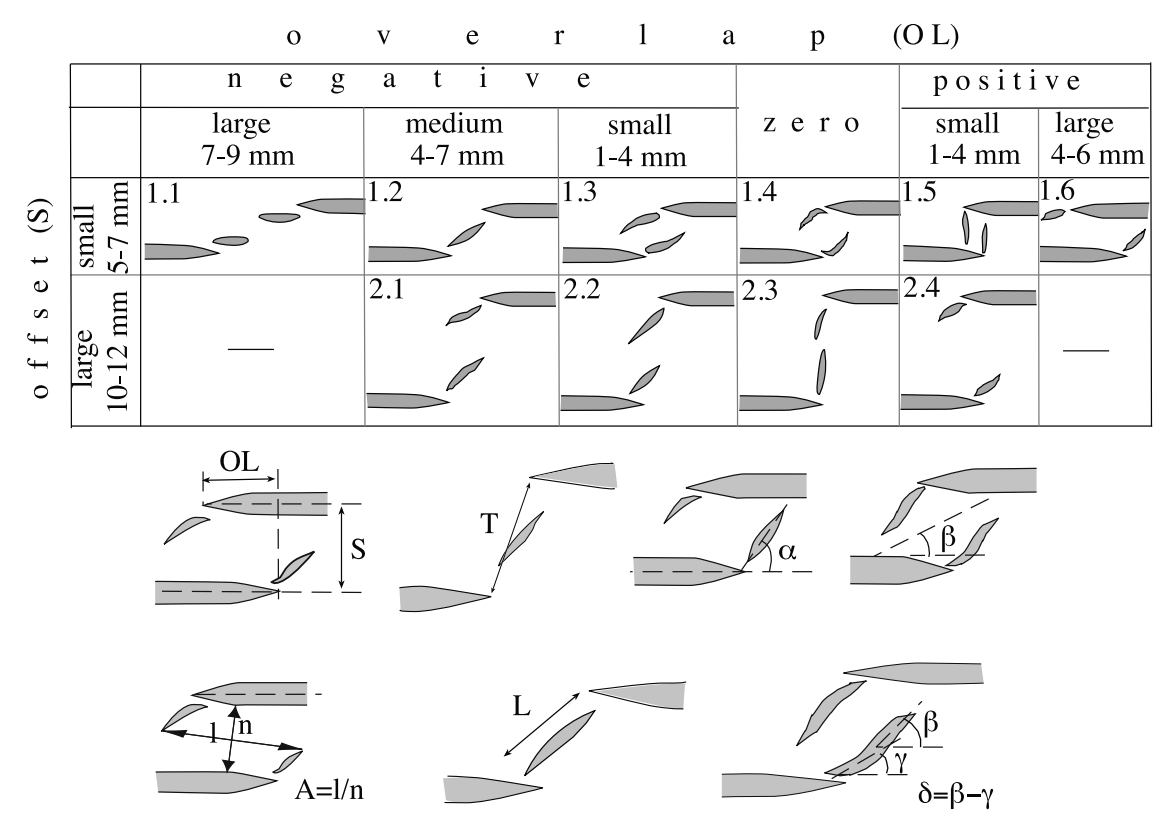

Figure 3. Types of interaction between two precut parallel fractures in the brittle layer of models and definition of the measured parameters: (1) fracture overlap (OL); (2) fracture offset (S); (3) aspect ratio of interaction zone (A); (4) fracture tip distance (T); (5) fracture length (L); (6) angle of fracture propagation $\alpha$; (7) angle of overlap elongation $\beta$; and (8) angle of fracture curvature $\delta$.

regard to the parent fractures $\left(20^{\circ}<\beta<40^{\circ}\right)$. Linkage is commonly observed.

[25] In type 1.5, fractures with smaller positive overlap $(1<\mathrm{OL}<4 \mathrm{~mm})$ interact by means of straight daughters $\left(0^{\circ}<\delta<10^{\circ}\right)$ at each tip, propagating almost perpendicularly to the parent fractures $\left(80^{\circ}<\alpha<90^{\circ}\right)$. This forms an interaction zone with limited aspect ratio $(1<\mathrm{A}<2)$, at high angle with regard to the parent fractures $\left(50^{\circ}<\beta<\right.$ $60^{\circ}$ ). Linkage between daughters, as well as minor shear along, is often observed.

[26] In type 1.6, fractures with larger positive overlap $(4<\mathrm{OL}<6 \mathrm{~mm})$ propagate through moderately curved fractures $\left(10^{\circ}<\delta<25^{\circ}\right)$, at high angle with regard to the parent fractures $\left(45^{\circ}<\alpha<55^{\circ}\right)$. This forms an interaction zone with aspect ratio $\mathrm{A}$ of $2-3.5$, at a significant angle with regard to the parent fractures $\left(40^{\circ}<\beta<50^{\circ}\right)$. The propagation of the fractures seldom leads to their linkage.

[27] In summary, decreasing the overlap (or the underlap) toward $\mathrm{OL}=0$ decreases the aspect ratio of the interaction zone (Figure 3), increasing the curvature of the newly formed fractures (Table 2). Therefore, fracture pairs with smaller OL form wider interaction zones, with curved paths, whereas those with larger OL form longer zones, with straight paths. Decreasing OL, the fractures in the interaction zone become oriented with a progressively higher angle $\alpha$ to the parent fractures; this reaches a maximum for small positive OL (with smaller S) or $\mathrm{OL} \sim 0$ (with larger $\mathrm{S}$ ) (Figure 4a).

[28] Considering a larger offset of $10<\mathrm{S}<12 \mathrm{~mm}$, four interaction types, with negative $(-7<\mathrm{OL}<-4 \mathrm{~mm})$ to positive (1-4 mm) overlap can be distinguished (2.1 to 2.4 in Figure 3). Fractures do not interact if $\mathrm{OL}$ exceeds these values (e.g., with $-7<\mathrm{OL}<-9 \mathrm{~mm}$ and $4<\mathrm{OL}<6 \mathrm{~mm}$ ), as shown by the lack of propagating (parents or daughters) fractures under these conditions. In general, in the four cases of large-offset interactions, daughters nucleate at each fracture tip, propagating toward the opposite fracture.

[29] In type 2.1, fracture pairs with larger $\mathrm{S}$ and medium negative underlap $(-7<\mathrm{OL}<-4 \mathrm{~mm})$ interact forming, at each tip, oblique fractures $\left(40^{\circ}<\alpha<50^{\circ}\right)$. These show a moderate variation in their curvature $\left(10^{\circ}<\delta<25^{\circ}\right)$ and moderate aspect ratio $(1.5<\mathrm{A}<2)$; the interaction zone is at a significant angle with regard to the parent fractures $\left(50^{\circ}<\beta<60^{\circ}\right)$.

[30] In type 2.2, in fracture pairs with a larger $\mathrm{S}$ and small negative underlap $(-4<\mathrm{OL}<-1 \mathrm{~mm})$, the propagating fractures have low curvature $\left(5^{\circ}<\delta<15^{\circ}\right)$. Their angle of propagation becomes higher $\left(45^{\circ}<\alpha<70^{\circ}\right)$ and their aspect ratio also increases $(2<\mathrm{A}<3)$, elongated at higher angle to the parent fractures $\left(60^{\circ}<\beta<70^{\circ}\right)$.

[31] In type 2.3 , in fracture pairs with a larger $\mathrm{S}$ and $\mathrm{OL}=0$, new fractures propagate almost orthogonal to the parent fractures $\left(65^{\circ}<\alpha<80^{\circ}\right)$. Their curvature is negligible $\left(0^{\circ}<\delta<10^{\circ}\right)$ and the aspect ratio of the interacting zone has the highest values $(3<\mathrm{A}<4)$, elongating perpendicularly to the parent fractures $\left(80^{\circ}<\beta<90^{\circ}\right)$.

[32] In type 2.4, in fracture pairs with a larger $\mathrm{S}$ and small positive overlap $(1<\mathrm{OL}<4 \mathrm{~mm})$, new cracks $\left(5^{\circ}<\delta<20^{\circ}\right)$ propagate with slightly curved paths, at a significant angle $\left(40^{\circ}<\alpha<65^{\circ}\right)$ to the parent fractures. The aspect ratio of the interaction zone decreases $(1<\mathrm{A}<2)$ and it is elongated at high angle to the parent fractures $\left(60^{\circ}<\beta<70^{\circ}\right)$.

[33] In summary, the four interaction types with larger $\mathrm{S}$ show that the daughters usually propagate at high angle to their parents, with low to moderate curvature (Figure 3 and Table 2). The aspect ratio A is the most variable parameter, increasing toward zero overlap values.

[34] The role of the offset $\mathrm{S}$ in the interaction is evaluated considering the differences among the interaction types with constant OL (Figure 3). A first effect of the increase of S is 

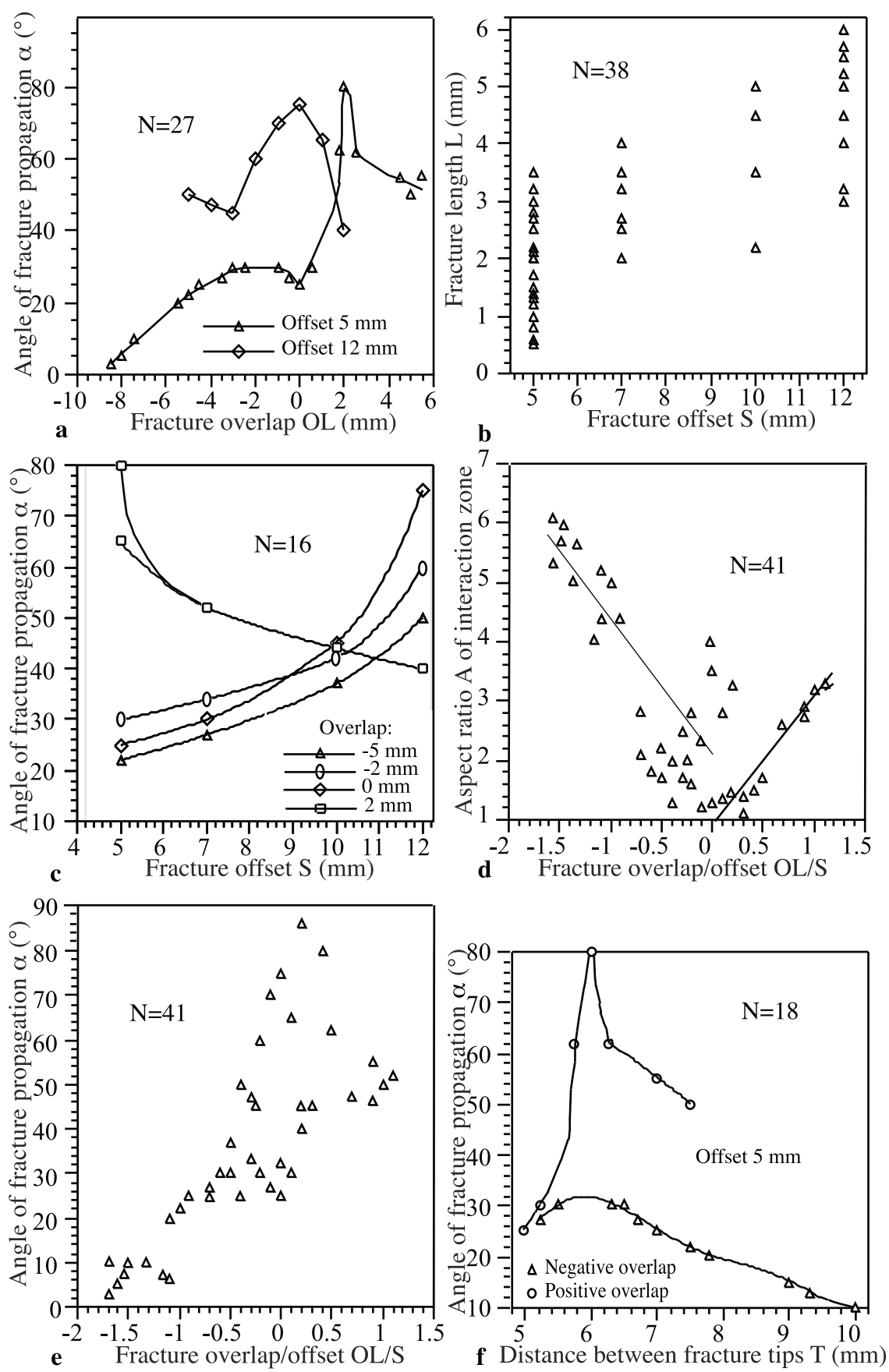

Figure 4. Relationships among experimental parameters. (a) fracture overlap OL versus the angle of propagation of a new fracture $\alpha$; (b) fracture offset $\mathrm{S}$ versus length $\mathrm{L}$ of a new fracture; (c) fracture offset $\mathrm{S}$ versus the angle of propagation of a new fracture $\alpha$; (d); fracture overlap/offset ratio $\mathrm{OL} / \mathrm{S}$ versus the aspect ratio A of the interaction zone; (e) fracture overlap/offset ratio $(\mathrm{OL} / \mathrm{S})$ versus the angle of propagation of a new fracture $\alpha$; and (f) distance between the fracture tips T versus the angle of propagation of a new fracture $\alpha$.

hindering the interaction of those fractures with larger overlap (or underlap). Most interactions with larger S did not reach the linkage stage, with one or both fracture tips remaining isolated, requiring a higher amount of strain to continue their propagation. Second, S appears to control the length of the newly formed fractures. There is a marked tendency for individual fractures to become longer before linking in fracture pairs with larger S (Figure 4b). A third effect of the increase of $\mathrm{S}$ is the development of fractures at higher angle with respect to their parent fractures. This is shown in Figure 4c, where the propagation angle $\alpha$ of the fractures varies as a function of $\mathrm{S}$, for various OL. In particular, in fractures with $\mathrm{OL} \leq 0, \alpha$ progressively increases with $\mathrm{S}$; conversely, in fractures with $\mathrm{OL}>0$, $\alpha$ decreases with $\mathrm{S}$. A fourth effect is the decrease of the fracture curvature $\delta$ (Table 2). A fifth effect is the overall increase of the aspect ratio A approaching $\mathrm{OL}=0$. In fact, conversely to what observed with smaller $\mathrm{S}$, the aspect ratio 



Figure 5. Variation in the direction of propagation of new fractures accommodating the experimental interactions in the models. Angle of fracture propagation $\alpha$ changes as a function of the fracture overlap OL by means of (a) curving fracture tips, (b) new isolated oblique fractures, (c) transform fractures and (d) summary of the three types of interactions.

of the interactions with larger $\mathrm{S}$ progressively increases as OL approaches zero (Table 2). Also, the elongation of the interaction zone rotates toward high angles with regard to the parent fractures (Table 2).

[35] The effect of the OL/S ratio on the deformation pattern has been also taken into account. As far as the overall shape of the interaction zone is concerned, the change of the aspect ratio A with $\mathrm{OL} / \mathrm{S}$ indicates that, when OL/S approaches both -1.5 and -1 , more elongated zones form (Figure $4 \mathrm{~d}$ ). The OL/S ratio also increases the propagation angle $\alpha$ (Figure 4e). This angle $\alpha$ also depends on the distance $\mathrm{T}(\mathrm{T}=\operatorname{arctg} \mathrm{S} / \mathrm{OL})$ between the tip of the fractures, if assuming a constant $\mathrm{S}(5 \mathrm{~mm}$ in the example considered; Figure 4f). For fracture pairs with negative overlap, $\alpha$ generally decreases smoothly with $\mathrm{T}$; for fractures with positive overlap, $\alpha$ first increases and then decreases with $\mathrm{T}$.

[36] Daughter fractures with small negative to zero overlap propagate along curved paths (types 1.3, 1.4, 1.6, 2.4), with $\alpha=25-32^{\circ}$; in fractures with small positive overlap, this angle may reach $\alpha=40-65^{\circ}$ and, in fractures with large positive overlap, it may reach $\alpha=45-55^{\circ}$ (Figure 5a). Straight daughter fractures propagating obliquely to their parents in large negative overlaps (types 1.1, 1.2, 2.1, 2.2) have $\alpha=3-10^{\circ}$, in medium negative overlaps have $\alpha=$ $20-50^{\circ}$ and in small negative overlaps have $\alpha=33-70^{\circ}$ (Figure 5b). Straight daughter fractures orthogonal to their parents and with small positive overlap (reminiscent of the transform configuration), have $\alpha=70-80^{\circ}$ (with $\mathrm{OL}=0$ ) and $\alpha=60-85^{\circ}$ (Figure 5c).

[37] Based on the relationships between the angle of propagation and the overlap of the fractures, three major modes of fracture interaction may be defined, as accommodated by (1) curving tips, (2) straight oblique, and (3) orthogonal (transform) fractures (Figure 5d). Fracture pairs interact by means of (1) curving tips with $\alpha=20-50^{\circ}$ (Figure 6a), when OL is small negative to large positive (Figure 5d); (2) oblique fractures propagating at a variety of angles $\left(\alpha=3-80^{\circ}\right.$; Figure $\left.6 \mathrm{~b}\right)$, when OL $<0$ (Figure $5 \mathrm{~d}$ ); and (3) transform segments with $\alpha=40-85^{\circ}$ (Figure 6c), when $\mathrm{OL}=0$ or small positive (Figure $5 \mathrm{~d}$ ). Thus, the variation of $\alpha$ with OL is most pronounced for interactions accommodated by oblique fractures and is least significant for interactions through transform-like fractures (Figure 5d).

\section{Discussion}

\subsection{Interpretation of the Experiments}

[38] The interaction between ridges simulated in the experiments commonly results in the development of overlap zones. In the early stages of interaction, the ridges grow along slightly diverging paths, which subsequently change into converging trajectories. Once the faster propagating ridge reaches the other and links with it, the less propagating ridge becomes locked.

[39] In general, in interactions with small offsets, overlaps approaching zero are responsible for the lowest aspect ratios of the interaction zone (Figure 3 and Table 2). The opposite is observed for interactions with larger offsets, where, with overlaps approaching zero, the interaction zones show highest aspect ratios, resulting from their narrowing, similarly to the oceanic TF. Therefore, the apparent inconsistent trend observed between the overlap and the aspect ratio of the interaction zone for smaller respective larger offsets may be explained by the change in the width of the interaction zone.

[40] The experimental results show that, in general, larger offsets hinder the interaction of those fractures associated with larger overlap or underlap. Therefore, there is a balance between the values of $\mathrm{OL}$ and $\mathrm{S}$ which allows interaction: 

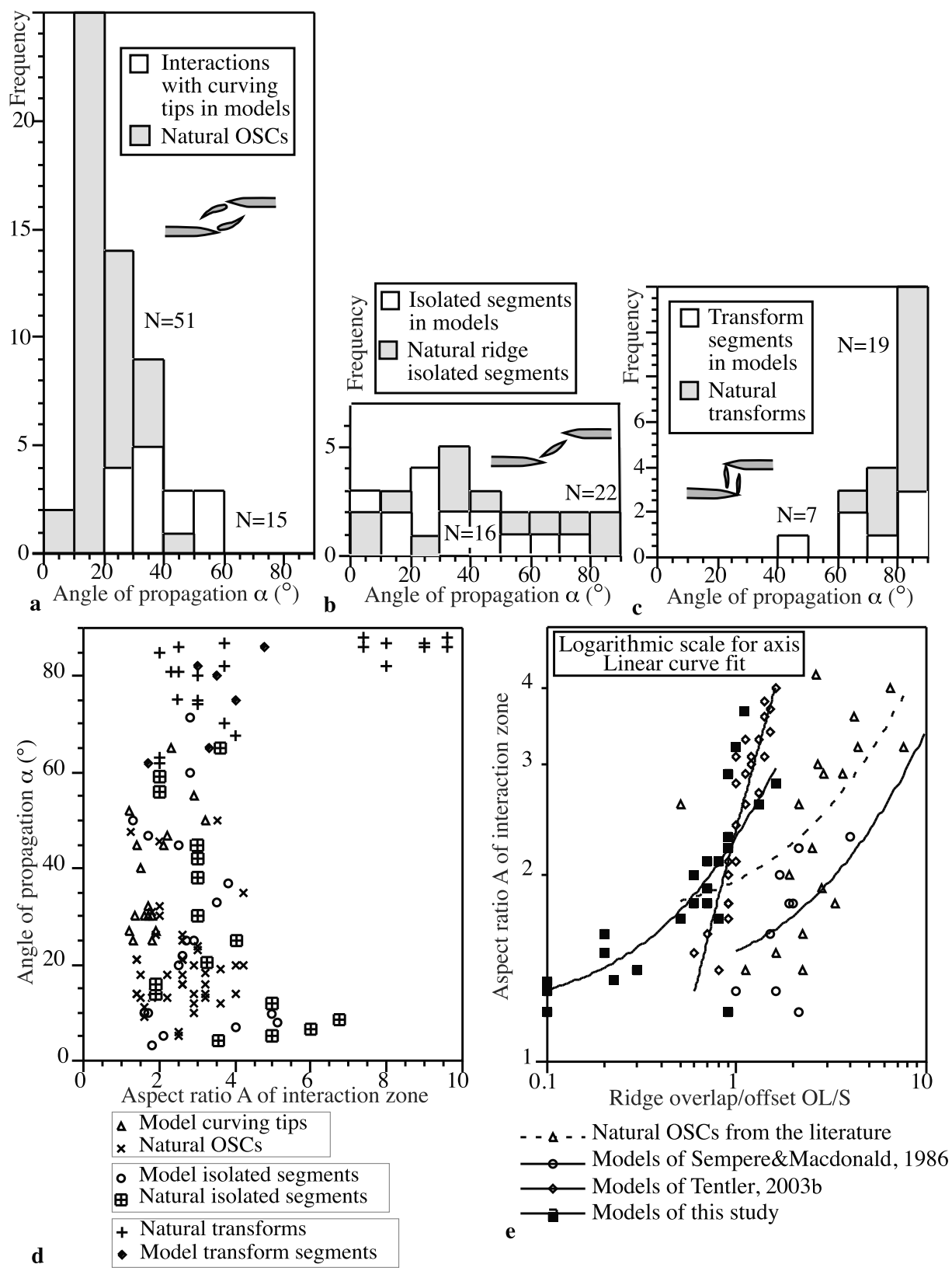

Figure 6. Geometric parameters of ridge interactions simulated in the models compared with those from previous studies of natural MORs. Distribution of the angle of ridge propagation $\alpha$ for interactions accommodated by (a) curving tips, (b) isolated fractures, and (c) transform segments. (d) Aspect ratio A of the interaction zone versus the angle of propagation $\alpha$. (e) Ridge overlap/offset ratio (OL/S) versus the aspect ratio $\mathrm{A}$ of the interaction zone.

the larger is $\mathrm{S}$, the lower must be the overlap (or underlap) to develop interaction. The propagating force of the crack tips is associated with a given strain and decreases with the increase in OL and S [Segall and Pollard, 1983]. This means that fractures too distant from each other will not interact. Accordingly to the obtained results, $\mathrm{S}$ has to be 1 order of magnitude smaller that the total length of the two fractures to have interaction (see discussion by Acocella [2008]). A similar ratio between OL and the total fracture length was recognized in other experimental models [Sempere and Macdonald, 1986; An, 1997; Tentler, 2003b] and for fractures along the oceanic ridge of Iceland [Acocella et al., 2000; Tentler and Mazzoli, 2005].
[41] An important feature related to the increase in $\mathrm{S}$ is the development of new straight fractures at high angles to their parent fractures, resembling transform-like structures. As discussed in more detail by Acocella [2008], these transform-like structures form when $\mathrm{S}$ is large compared to their total length; however, higher amounts of extension and an additional, minor ridge-parallel extension are also required for development of transform-like structures. The presence of transform-like structures related to higher $\mathrm{S}$ is consistent with previous modeling results [Shemenda and Grocholsky, 1991, 1994; Thomas and Pollard, 1993] and confirms that straight transverse segments are likely to form 
between widely spaced ridges, whereas closely spaced ridges interact by their tips propagating along curved paths.

[42] In general, the different types of interactions in Figure 3, as well as the variations in the incremental and finite strain during the interaction (Figures $2 \mathrm{~h}-2 \mathrm{j}$ ), result from the stress distribution due to different configurations of fractures in pairs. The tips of the fractures, as well as the overlapping area within, are the most strained regions during the interaction stage (Figures $2 \mathrm{~h}-2 \mathrm{j}$ ). This is explained by the fact that the highest concentration of tensile and shear stresses is achieved at the tips of the propagating fractures; as a result, the superposition of high stress intensity fields at two closely spaced fracture tips facilitates their mutual interaction [Pollard and Aydin, 1984; McKenzie, 1986]. The large spectrum of fracture interaction geometries observed in the experiments may thus be explained by distinct patterns of their stress fields cooperation. In fact, stress fields at each fracture tip, as well as their superimposition, affect the distribution of the strain, defining the overall geometric and kinematic features of the interaction zone. Configuration of high stress intensity fields of variously positioned fractures in interacting pairs [Pollard and Aydin, 1984] suggests that an increase of S enhances the shear stresses, while an increase in the overlap (or underlap) enhances the normal stresses. Therefore, S and OL are expected in general to impose opposite effects on the distribution of the stresses within an interaction zone.

[43] Our experimental results significantly expand the range of ridge interaction geometries considered in previous modeling studies [Sempere and Macdonald, 1986; Shemenda and Grocholsky, 1991, 1994; Katz et al., 2005; Tentler, 2007; Acocella, 2008]. Among these, the experiments of Tentler [2003a, 2003b, 2007] have shown how the configuration of the spreading systems is influenced by the location and orientation of the ridge segments for the limited range of interaction geometries. Our experimental data set and results are also more comprehensive than those of Acocella [2008], based on a limited number of experiments and considering only the ratio between the fracture length and overlap to form end-member interaction types (OSC and TF). Acocella [2008] proposed that the development of transform-like features depends, in addition to the initial configuration of the fractures, also on the presence of a minor fracture-parallel extension. While we confirm the general lines of Tentler [2003a, 2003b, 2007] and Acocella [2008], a significantly broader spectrum of interaction types, transitional between OSC and TF, may be here considered and discussed as a function of the initial overlap and offset values.

\subsection{Comparison to Natural Systems}

[44] The present study did not address specifically the origin of various configurations of isolated segments along ridges rather, it attempted to investigate mechanisms driving interaction of already existing segments. Our results show that regardless of the processes responsible for the initial development of ridge segments, the geometry of the interaction zone and linkage pattern of the segments are largely dependent upon their initial configuration.

[45] While it is generally accepted that instabilities in the spreading direction increase the structural complexity of oceanic ridges [Dauteuil and Brun, 1993; Macdonald,
1998; Mart and Dauteuil, 2000], there is a debate on whether this should be considered as a primary control on the formation of OSC. Thus while Macdonald et al. [1984, 1988] suggested that a change in the direction of spreading might lead to a preferred sense of offset of OSC, Lonsdale [1985, 1986] argued that OSC ultimately result from a change in the relative motion of the accreting plates. Recently, Katz et al. [2005] proposed that OSC develops predominantly on obliquely spreading ridges, with the ridge striking at $\sim 45^{\circ}$ from the spreading direction. The present experiments, with different OSC developing from fractures orthogonal to the extension direction, indicate that oblique spreading is not required to form OSC.

[46] The variable degree of interaction in the experimental OSC affects the possibility to produce isolated domains, acting as tectonic microplates in nature and recognized on different scales along MORs [Schouten et al., 1993; Neves et al., 2003]. While it is generally considered that microplates grow through crustal accretion from encircling spreading boundaries [Macdonald and Fox, 1983; Naar and Hey, 1991], our experiments suggest that microplate development is most likely for small offset and zero-overlap ridge configurations (type 1.4 in Figure 3); in fact, these configurations evolve toward a complete linkage. The development of microplates is likely to be hindered at ridges with large overlap (type 1.6) or offset (type 2.4), as these configurations have a low probability to reach the linkage stage. The crucial condition for the development of microplates is the bypassing of the overlap configuration, to achieve the complete isolation of the overlap domain. This isolation is accomplished by the linkage of both ridge tips, more commonly sequential, rather than simultaneous.

[47] The principles of dynamic scaling employed in the present modeling [Ramberg, 1981] allow the comparison of the experimental fracture patterns with more than 100 previously described natural examples of ocean ridge interactions [Lonsdale, 1985, 1986; Huang et al., 1986; Langmuir et al., 1986; Sempere and Macdonald, 1986; Macdonald et al., 1988; Severinghaus and Macdonald, 1988; Mutter and Karson, 1992; Kent et al., 1993; Wang and Cochran, 1993; Carbotte and Macdonald, 1994; Devey et al., 1994; Lagabrielle et al., 1998; Macdonald, 1998; Cochran et al., 2003; Tivey et al., 2003].

[48] From a general point of view, a qualitative comparison shows that most interaction types between natural ridges may be related to specific experimental cases (Figure 7). In particular, ridges whose underlap largely exceeds their offset propagate toward each other at low angles, through straight segments (Figures $7 \mathrm{e}$ and $7 \mathrm{~h}$ ), similarly to experimental interaction types 1.1 and 1.2. In particular, this occurs along EPR, near $12^{\circ} 15^{\prime}$ (Figure $7 \mathrm{~h}$ ) and in the Kolbeinsey Ridge, along northern MAR (Figure 7e). Closely spaced ridges with small negative to zero overlap propagate with gradually increasing angles forming hookshaped OSC (Figures 7b, 7c, and 7g), as observed in interaction types 1.3 and 1.4. For example, this occurs along EPR, near $9^{\circ}$ (Figure 7c, similar to type 1.3 interaction) and near $-8^{\circ} 30^{\prime}$ to $9^{\circ}$ (Figure $7 \mathrm{~g}$ ), similar to type 1.4 interactions. Ridges whose overlap largely exceeds their offset propagate by slightly curved tips at low angles (Figure 7f), as seen in interaction type 1.6. In particular, this occurs along EPR near $5^{\circ} 5^{\prime}$, where an OSC has appar- 

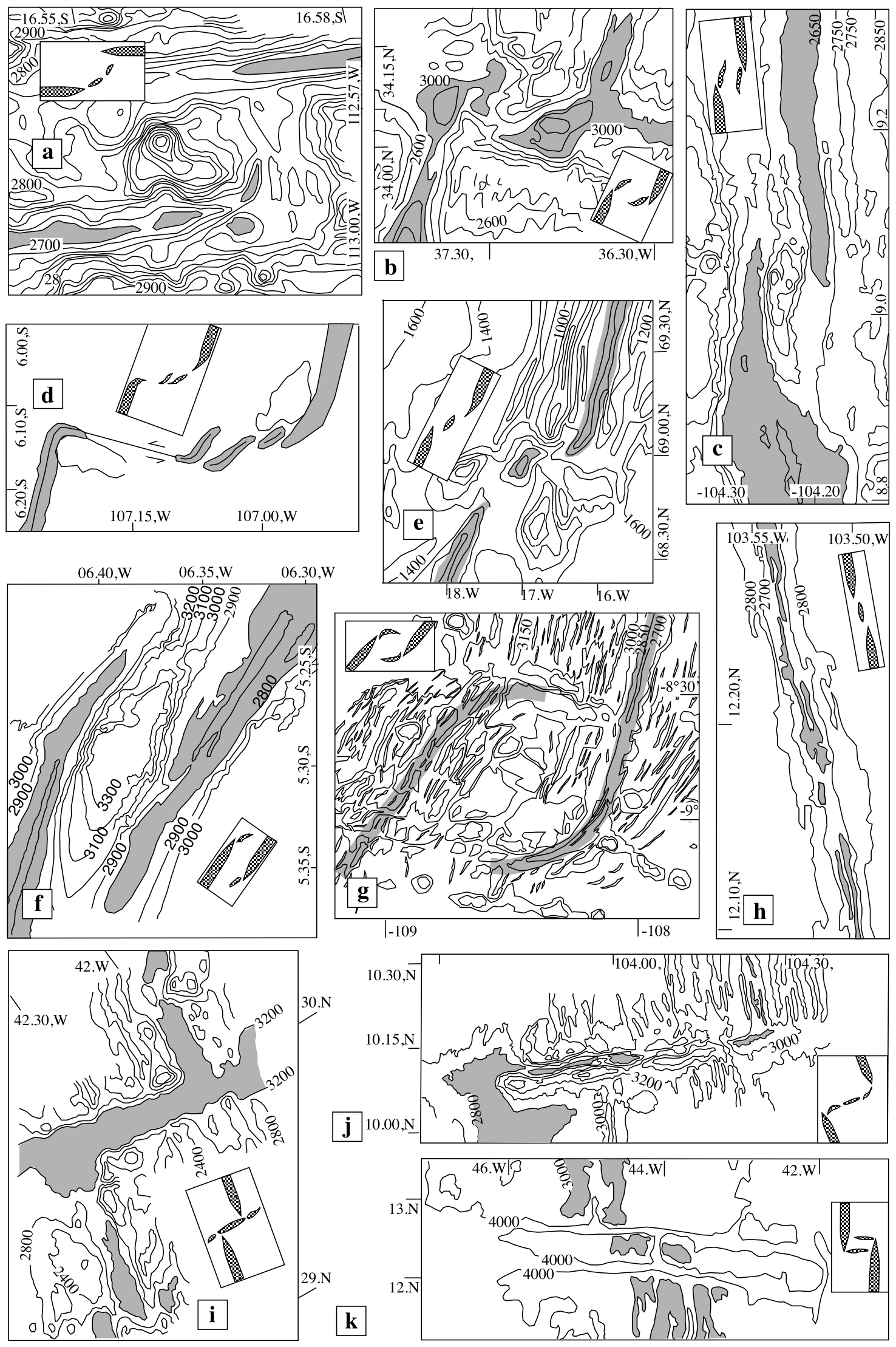

Figure 7 
ently achieved an advanced stage of interaction (Figure $7 \mathrm{f}$ ). Ridges with offset greatly exceeding their overlap (or underlap) interact developing straight oblique to orthogonal segments (Figures $7 \mathrm{a}$ and $7 \mathrm{~d}$ ), similarly to interaction types 2.1-2.3. Thus this is observed along EPR, where a ridge segment becomes nearly orthogonal to the other ridge (Figure 7a) and where the Yaquina transform zone is forming (Figure 7d). Most commonly, transform-like structures develop between ridges with overlap approaches zero or when S largely exceeds OL (Figures $7 \mathrm{i}$ and $7 \mathrm{j}$ ), whereas multiple fracture zones form when OL value approaches $\mathrm{S}$ (Figure 7k). In particular, examples of the first case are the Atlantis Fracture Zone, along MAR (Figure 7i), and Clipperton Transform, along EPR (Figure $7 \mathrm{j}$ ), both reminiscent of interaction type 2.3. Examples of the second case are the multiple fracture zones along MAR at $12-13^{\circ}$ (Figure $7 \mathrm{k}$ ), similar to interaction type 1.5 .

[49] In general, this qualitative comparison between experiments and nature suggests that the interaction of oceanic ridges is scale independent and largely controlled by their initial configuration.

[50] From a more quantitative point of view, interacting fractures in the experiments propagate toward each other with angles $\alpha$ being similar to those of interacting ridges in nature (Figures $6 \mathrm{a}-6 \mathrm{c}$ ). Structures propagating along curved paths show $\alpha<60^{\circ}$ (mainly 10-40; Figure 6a). These moderate angles of propagation and marked curvature of ridge segments are characteristic for ultrafast to fast spreading ridges with typical small negative segment overlaps and offsets [Macdonald, 1998; Hey et al., 2004]. In interactions by means of straight oblique segments, $\alpha$ varies largely $\left(0-90^{\circ}\right.$; Figure $\left.6 \mathrm{~b}\right)$. These interaction configurations appear to be most common along MORs spreading at intermediate rates, with moderate overlaps and offsets [Sempere et al., 1997; Perfit and Chadwick, 1998; Small, 1998]. Transform-like structures in the experiments and nature show $\alpha>40^{\circ}$ (mainly 60-90 ; Figure 6c). These high angles of propagation appear to prevail during ridge interaction along slow spreading MORs with stable configurations [Kong et al., 1988; Briais et al., 2000; Tivey et al., 2003] and along doomed ridges failing to develop in continuous plate boundaries [Hey et al., 1986; McKenzie, 1986].

[51] The relationships between $\alpha$ and the aspect ratio $\mathrm{A}$ for ridges simulated in the experiments are fairly similar to those in nature [Lonsdale, 1985, 1986; Huang et al., 1986; Langmuir et al., 1986; Sempere and Macdonald, 1986; Macdonald, 1988; Severinghaus and Macdonald, 1988;
Mutter and Karson, 1992; Kent et al., 1993; Wang and Cochran, 1993; Carbotte and Macdonald, 1994; Devey et al., 1994; Lagabrielle et al., 1998; Macdonald et al., 1998; Cochran et al., 2003; Tivey et al., 2003] for each of the three major groups of interaction (curving tips, transform-like and oblique straight segments; Figure $6 \mathrm{~d}$ ). The OL/S ratio versus $A$ of the experimental ridges (Figure 6e) shows an overall linear relationship, with a moderate scatter, consistently with previous numerical [Sempere and Macdonald, 1986] and analogue studies [Tentler, 2003b] as well as natural OSC. This consistency emphasizes the inheritance of the initial configuration of the ridges on their overall shape.

[52] The experimental results suggest that ridge interactions in nature may either be (1) a transient feature reflecting minor fluctuations in the location of the spreading axes, rapidly followed by linkage (particularly common in interaction types $1.1,1.4,1.5)$, as suggested by Macdonald et al. [1984] and Schouten et al. [1985] or (2) impose a longlasting effect on the geometry of the plate boundary (common in types $1.6,2.1,2.2,2.4$ ), where overlapping configurations may significantly reorient the local spreading direction [Hey et al., 1986]. The experiments show that ridge segment linkage not only highlights the irregularity of the plate boundary, as occurs along large portions of EPR [Macdonald et al., 1988, 1991, 1992], but also complicates the spreading configurations through long-lasting geometries, as along MAR [Kong et al., 1988; Purdy et al., 1990; Briais et al., 2000].

[53] The models also suggest that the interaction of ridge segments may proceed in two main modes: (1) along narrow bands of highly localized deformation (particularly common in interaction types $1.1,1.2,2.3$ ) as proposed by Schouten et al. [1985] and Sempere and Macdonald [1986] and (2) in broad zones of diffuse extension (particularly common in widely spaced ridges of 2.1, 2.2, 2.4 types), as advocated by Hey et al. [1986] and McKenzie [1986]. In the first case, the propagation of the interacting ridges is associated with migration of the strain focused along a narrow zone connecting ridge tips and inducing aligned segments. Along natural MORs, such a ridge interaction is expected to be characterized by a magmatism being focused at the ridge tip and by extensional faults focused within a linear zone ahead of it [Kleinrock et al., 1997; Hey et al., 2004]. The second case of diffuse ridge interaction is associated with strain partitioning along new segments oriented obliquely in respect to the interacting ridges. In nature such a mode of interaction is likely to develop

Figure 7. Examples of interactions between spreading ridges from bathymetric maps: (a) EPR, Pacific-Nazca offset, contour interval $20 \mathrm{~m}$, the area deeper than $2800 \mathrm{~m}$ is shaded [from Lonsdale, 1986]; (b) MAR, the OH3 segment, contour interval $300 \mathrm{~m}$, the area deeper than $3000 \mathrm{~m}$ is shaded [from Lagabrielle et al., 1998]; (c) EPR, OSC near $9^{\circ}$, contour interval $100 \mathrm{~m}$, the area deeper than $2650 \mathrm{~m}$ is shaded [from Kent et al., 1993]; (d) EPR, Yaquina transform zone, plan pattern of the rise crest [from Lonsdale, 1983]; (e) MAR, Kolbeinsey ridge, contour interval $200 \mathrm{~m}$, the axial ridge area is shaded [from Devey et al., 1994]; (f) EPR, OSC near 5 5'S, contour interval $100 \mathrm{~m}$, the area deeper than $2800 \mathrm{~m}$ is shaded [from Lonsdale, 1986]; (g) EPR, OSC near $-8^{\circ} 30^{\prime}-9^{\circ} \mathrm{S}$, contour interval $150 \mathrm{~m}$, the axial ridge area is shaded [from Wang and Cochran, 1993]; (h) EPR, offset near $12^{\circ} 15^{\prime} \mathrm{N}$, contour interval $100 \mathrm{~m}$, the area deeper than $2600 \mathrm{~m}$ is shaded [from Langmuir et al., 1986]; (i) MAR, Atlantis Fracture Zone, contour interval $400 \mathrm{~m}$, the area deeper than $3200 \mathrm{~m}$ is shaded [from Mutter and Karson, 1992]; (j) EPR, Clipperton Transform, contour interval $200 \mathrm{~m}$, the area deeper than $2800 \mathrm{~m}$ is shaded [from Severinghaus and Macdonald, 1988]; and (k) MAR, fracture zones near $12^{\circ} \mathrm{N}-13^{\circ} \mathrm{N}$, contour interval $1000 \mathrm{~m}$, the area shallower than $3000 \mathrm{~m}$ is shaded [from Huang et al., 1986]. 



Figure 8. (a) Frequency of the proposed types (Figure 3) of segment interaction along oceanic ridges. Frequency of various parameters characterizing the interaction between ridges in the models and along natural MORs: (b) aspect ratio A of the interaction zone, (c) angle of propagation $\alpha$, (d) segment curvature $\delta$, and (e) elongation angle $\beta$ of the interaction zone.

magmatic centers and faults of varied orientation distributed over a wider domain [Kleinrock et al., 1989; Kleinrock and Hey, 1989].

[54] The experiments allow recognizing a spectrum of ridge interaction geometries wider than previously described [Macdonald et al., 1988; Shemenda and Grocholsky, 1991, 1994; Gudmundsson, 1995a, 1995b; Taylor et al., 1994; Macdonald, 1998; Cochran et al., 2003; Tivey et al., 2003]. In this spectrum, TF and OSC do not appear as the exclusive types of interaction between spreading centers. Analyses of published maps of various portions of MORs (see Lonsdale [1985, 1986], Huang et al. [1986], Langmuir et al. [1986], Sempere and Macdonald [1986], Macdonald et al. [1988], Severinghaus and Macdonald [1988], Mutter and Karson [1992], Kent et al. [1993], Wang and Cochran [1993], Carbotte and Macdonald [1994], Devey et al. [1994], Lagabrielle et al. [1998], Macdonald [1998]; Cochran et al. [2003], Tivey et al. [2003] and additional studies from Lonsdale [1983], Kong et al. [1988], Kuo and Forsyth [1988], Kastens et al. [1998], Auzende et al. [1990, 1995], McClain and Wright [1990], Purdy et al. [1990], Mutter and Karson [1992], Enriquez and Chen [1995], Appelgate [1997], Krasnov et al. [1997], Embley et al. [1998], Pardee et al. [1998], Briais et al. [2000], Dziak et al. [2000, 2001], Crane et al. [2001], Hébert et al. [2001], Wilcock et al. [2002], Flores-Marquez et al. [2003], Hosford et al. [2003],
Kopp et al. [2003], Okino and Fujioka [2003], Shah et al. [2003], and Chadwick et al. [2005]) shows that many types of interactions may be identified along ridges (Figure 8a), consistently with the experimental types of Figure 3. Not surprisingly, of all the 104 considered ridge interactions, the most common developed through OSC with curved tips (type $1.3 ; 27 \%$ ) and transform segments (type $2.3 ; 25 \%$ ). The remaining $48 \%$ of the interactions belong to the other types identified in this study, of which the most common are those of subparallel (type $1.1 ; 12 \%$ ) or oblique (type 1.2; $13 \%$ ) propagating segments.

[55] The shape of the overlap zone between ridges in nature tends to be elliptical, with highly varied elongation and aspect ratio $\mathrm{A}<8$ (mainly $\mathrm{A}<5$ ), consistently with the experiments, where $\mathrm{A}<6$ (Figure $8 \mathrm{~b}$ ). The angle of ridge propagation $\alpha$ in nature shows a wide range of values, with dominating $20^{\circ}<\alpha<30^{\circ}$ and $80^{\circ}<\alpha<90^{\circ}$, whereas any preference in the models is poorly expressed, with only a slight tendency to $20^{\circ}<\alpha<60^{\circ}$ (Figure 8c). Curvature $\delta$ of the linking ridge segments in nature, although approaching $40^{\circ}$ in a few examples, is largely limited to $25^{\circ}$, with the distribution being similar to that in the models (Figure 8d). The angle $\beta$ of the elongation of overlap zone of the natural ridges is highly varied, with characteristic $20^{\circ}<\beta<40^{\circ}$ and $80^{\circ}<\beta<90^{\circ}$ corresponding to those of $20^{\circ}<\beta<40^{\circ}$ and $50^{\circ}<\beta<70^{\circ}$ in the experiments (Figure 8e). The distribu- 
tion of the orthogonal linking segments with $\alpha$ and $\beta$ approaching $90^{\circ}$ in the models, as different to that in nature (Figures $8 \mathrm{c}$ and $8 \mathrm{e}$ ), may result from the imposed experimental simplifications. In fact, several modeling limitations (as the restricted range of the offset values, the homogeneity of the brittle layer, the insufficient longevity of spreading and the failure to simulate magma crystallization processes) may contribute to the scarcity of orthogonal structures in the experiments.

[56] The distinguished types of ridge interaction in the models (Figure 3 ) are major reference configurations, with possible hybrids in between, resulting from minor variations in the initial geometry of ridges or even from boundary conditions not considered in our experiments. The comparison between experiments and nature suggests that any type of interaction between spreading ridges should be placed in the geometric and kinematic context of the observed spectrum of configurations, and attributed to one of the reference types of interaction.

\section{Conclusions}

[57] 1. The experimental ridges propagate along-strike during their growth, by means of new segments nucleated at their tips. In general, ridge propagation leads to interaction and, eventually, linkage.

[58] 2. The experimental pattern allows to distinguish a much wider spectrum of ridge interaction types than previously recognized. The type of interaction depends upon the initial configuration of the ridges, resulting in a wide variety of orientation and curvature of newly developed ridge segments.

[59] 3. In ridge pairs with closely located segment tips, overlapping configurations and linkages are enhanced. Where the ridge tips have large overlap or offset, interaction is limited and the ridges commonly become temporarily locked. Transform-like structures may develop with higher amounts of extension and an additional ridge-parallel extension [Acocella, 2008].

[60] 4. Experimental OSCs with different geometric and kinematic features develop under a constant extension direction, indicating that any obliquity of the spreading direction is not crucial for their formation.

[61] 5. Ridge interaction zones may be transient features, reflecting minor variations in the position of the spreading axes, with rapid linkage. Alternatively, they may have a long-lasting control on the geometry of the ridge, whose tips remain permanently isolated, imposing persisting distortions in the local spreading direction.

[62] 6. The formation of a separate tectonic microplate is enhanced under small offset and zero-overlap ridge configurations, and results from the interaction and complete linkage between curved hook-shaped tips of both propagating ridges.

[63] 7. The history of the propagation and linkage of oceanic ridges may be usually reconstructed analyzing the geometric and kinematic features of divergent plate boundaries.

[64] Acknowledgments. C. Talbot and G. Mulugeta provided helpful suggestions. The experiments, performed during the Ph.D. of V.A., at the Dipartimento di Scienze della Terra, University of Siena, and the Ph.D. of
T.T., at the Department of Earth Sciences, Uppsala University, were partly financed by CNR funds (responsible A. Lazzarotto, University of Siena).

\section{References}

Acocella, V. (2008), Transform faults or overlapping spreading centers? Oceanic ridge interactions revealed by analogue models, Earth Planet. Sci. Lett., 265, 379-385, doi:10.1016/j.epsl.2007.10.025.

Acocella, V., A. Gudmundsson, and R. Funiciello (2000), Interaction and linkage of extension fractures and normal faults: Examples from the rift zone of Iceland, J. Struct. Geol., 22, 1233-1246, doi:10.1016/S01918141(00)00031-6.

An, L. (1997), Maximum link distance between strike-slip faults: Observations and constraints, Pure Appl. Geophys., 150, 19-36, doi:10.1007/ s000240050061

Appelgate, B. (1997), Modes of axial reorganization on a slow-spreading ridge: The structural evolution of Kolbeinsey Ridge since $10 \mathrm{Ma}$, Geology, 25, 431-434, doi:10.1130/0091-7613(1997)025<0431: MOAROA $>2.3 . \mathrm{CO} ; 2$

Auzende, J.-M., et al. (1990), Active spreading and hydrothermalism in North Fiji Basin (SW Pacific). Results of Japanese French Cruise Kaiyo 87, Mar. Geophys. Res., 12, 269-283, doi:10.1007/BF02428198.

Auzende, J.-M., R. Hey, B. Pelletier, D. Rouland, Y. Lafoy, E. Gracia, and P. Huchon (1995), Propagating rift west of the Fiji Archipelago (North Fiji Basin, SW Pacific), J. Geophys. Res., 100(B9), 17,823-17,835, doi:10.1029/95JB00612.

Benes, V., and S. Scott (1996), Oblique rifting in the Havre Trough and its propagation into the continental margin of New Zealand: Comparison with analogue experiments, Mar. Geophys. Res., 18, 189-201, doi:10.1007/BF00286077.

Bergerat, F., A. Gudmundsson, J. Angelier, and S. Rognvaldsson (1998), Seismotectonics of the central part of the South Iceland Seismic Zone, Tectonophysics, 298, 319-335, doi:10.1016/S0040-1951(98)00191-7.

Bjarnason, I., P. Cowie, M. Anders, L. Seeber, and C. Scholz (1993), The 1912 Iceland earthquake rupture: Growth and development of a nascent transform system, Bull. Seismol. Soc. Am., 83, 416-435.

Bonatti, E. (1985), Punctiform initiation of seafloor spreading in the Red Sea during transition from a continental to an oceanic rift, Nature, 316 33-37, doi: $10.1038 / 316033 \mathrm{a} 0$

Briais, A., H. Sloan, L. Parson, and B. Murton (2000), Accretionary processes in the axial valley of the Mid-Atlantic Ridge $27^{\circ} \mathrm{N}-30^{\circ} \mathrm{N}$ from TOBI side-scan sonar images, Mar. Geophys. Res., 21, 87-119, doi:10.1023/A:1004722213652.

Carbotte, S., and K. Macdonald (1994), The axial topographic high at intermediate and fast spreading ridges, Earth Planet. Sci. Lett., 128, 85-97, doi:10.1016/0012-821X(94)90137-6.

Chadwick, J., M. Perfit, I. Ridley, I. Jonasson, G. Kamenov, W. Chadwick, R. Embley, P. le Roux, and M. Smith (2005), Magmatic effects of the Cobb hot spot on the Juan de Fuca Ridge, J. Geophys. Res., 110, B03101, doi:10.1029/2003JB002767.

Cochran, J., G. Kurras, M. Edwards, and B. Coakley (2003), The Gakkel Ridge: Bathimetry, gravity anomalies, and crustal accretion at extremely slow spreading rates, J. Geophys. Res., 108(B2), 2116, doi:10.1029 2002JB001830

Crane, K., H. Doss, P. Vogt, E. Sundvor, G. Cherkashov, I. Poroshina, and D. Joseph (2001), The role of the Spitsbergen shear zone in determining morphology, segmentation and evolution of the Knipovich Ridge, Mar. Geophys. Res., 22, 153-205, doi:10.1023/A:1012288309435.

Dauteuil, O., and J. Brun (1993), Oblique rifting in a slow-spreading ridge, Nature, 361, 145-148, doi:10.1038/361145a0.

Dauteuil, O., O. Bourgeois, and T. Mauduit (2002), Lithosphere strength controls oceanic transform zone structure: Insights from analogue models, Geophys. J. Int., 150, 706-714, doi:10.1046/j.1365-246X. 2002.01736.x.

Devey, C., C. Garbe-Schnberg, P. Stoffers, C. Chauvel, and D. Mertz (1994), Geochemical effects of dynamic melting beneath ridges: Reconciling major and trace element variations in Kolbeinsey (and global) midocean ridge basalt, J. Geophys. Res., 99(B5), 9077-9095, doi:10.1029/ 93JB03364.

Dziak, R., C. Fox, R. Embley, J. Nabelek, J. Braunmiller, and R. Koski, (2000), Recent tectonics of the Blanco Ridge, eastern Blanco transform fault zone, Mar. Geophys. Res., 21, 423-450, doi:10.1023/ A: 1026545910893

Dziak, R., C. Fox, A. Bobbitt, and C. Goldfinger (2001), Bathymetric Map of the Gorda Plate: Structural and geomorphological processes inferred from multibeam surveys, Mar. Geophys. Res., 22, 235-250, doi:10.1023 A:1014606407111.

Embley, R., J. Lupton, G. Massoth, T. Urabe, V. Tunnicliffe, D. Butterfield, T. Shibata, O. Okano, M. Kinoshita, and K. Fujioka (1998), Geological, chemical, and biological evidence for recent volcanism at $17.5^{\circ} \mathrm{S}$ : East Pacific Rise, Earth Planet. Sci. Lett., 163, 131-147, doi:10.1016/S0012$821 \mathrm{X}(98) 00181-2$. 
Enriquez, K., and Y. Chen (1995), A three-dimensional gravity study of the Pacific-Antarctic East Pacific Rise/Menard transform intersection, J. Geophys. Res., 100(B9), 17,813-17,822, doi:10.1029/95JB01056.

Flores-Marquez, L., E. Surinach, J. Galindo-Zaldivar, and A. Maldonado (2003), Three-dimensional gravity inversion model of the deep crusta structure of the central Drake Passage (Shackeleton Fracture Zone and West Scotia Ridge, Antarctica), J. Geophys. Res., 108(B9), 2445, doi:10.1029/2002JB001934

Gudmundsson, A. (1995a), Ocean-ridge discontinuities in Iceland, J. Geol. Soc. London, 152, 1011-1015.

Gudmundsson, A. (1995b), Stress fields associated with oceanic transform faults, Earth Planet. Sci. Lett., 136, 603-614, doi:10.1016/0012$821 \mathrm{X}(95) 00164-8$

Gudmundsson, A., and S. Brynjolfsson (1993), Overlapping rift-zone segments and the evolution of the South Iceland Seismic Zone, Geophys Res. Lett., 20, 1903-1906, doi:10.1029/93GL01888.

Hayward, N., and C. Ebinger (1996), Variation in the along-axis segmentation of the Afar Rift system, Tectonics, 15, 244-257, doi:10.1029/ 95TC02292.

Hébert, H., C. Deplus, P. Huchon, and K. Khanbari (2001), Lithospheric structure of a nascent spreading ridge inferred from gravity data: The western Gulf of Aden, J. Geophys. Res., 106(B11), 26,345-26,363, doi:10.1029/2000JB900391.

Hey, R. (1977), A new class of "pseudofaults" and their bearing on plate tectonics: A propagating rift model, Earth Planet. Sci. Lett., 37, $321-$ 325, doi:10.1016/0012-821X(77)90177-7.

Hey, R., M. Kleinrock, S. Miller, T. Atwater, and R. Searle (1986), Sea Beam/Deep-Tow investigation of an active oceanic propagating rift system, Galapagos $95.5^{\circ} \mathrm{W}, J$. Geophys. Res., 91(B3), 3369-3393, doi:10.1029/JB091iB03p03369.

Hey, R., et al. (2004), Tectonic/volcanic segmentation and controls on hydrothermal venting along Earth's fastest seafloor spreading system, EPR $27^{\circ}-32^{\circ} \mathrm{S}$, Geochem. Geophys. Geosyst., 5, Q12007, doi:10.1029/ 2004GC000764.

Hosford, A., M. Tivey, T. Matsumoto, H. Dick, H. Schouten, and H. Kinoshita (2003), Crustal magnetization and accretion at the Southwest Indian Ridge near the Atlantis II fracture zone, 0-25 Ma, J. Geophys. Res., 108(B3), 2169, doi:10.1029/2001JB000604.

Huang, P., S. Solomon, E. Bergman, and J. Nabelek (1986), Focal depths and mechanisms of Mid-Atlantic Ridge earthquakes from body wave inversion, J. Geophys. Res., 91(B1), 579-598, doi:10.1029/ JB091iB01p00579.

Kastens, K., E. Bonatti, D. Caress, G. Carrara, O. Dauteuil, G. FruehGreen, M. Ligi, and P. Tartarotti (1998), The Vema Transverse Ridge (Central Atlantic), Mar. Geophys. Res., 20, 533-556, doi:10.1023/ A:1004745127999.

Katz, R., R. Ragnarsson, and E. Bodenschatz (2005), Tectonic microplates in a wax model of sea-floor spreading, New J. Phys., 7, 37, doi:10.1088/ $1367-2630 / 7 / 1 / 037$

Kent, G., A. Harding, and J. Orcutt (1993), Distribution of magma beneath the East Pacific Rise near the $9^{\circ} 03^{\prime} \mathrm{N}$ overlapping spreading center from forward modeling of common depth point data, J. Geophys. Res., 98(B8), 13,971-13,995, doi:10.1029/93JB00706.

Kleinrock, M., and R. Hey (1989), Migrating transform zone and lithospheric transfer at the Galapagos $95.5^{\circ} \mathrm{W}$ propagator, J. Geophys. Res., 94(B10), 13,859-13,878, doi:10.1029/JB094iB10p13859.

Kleinrock, M., R. Searle, and R. Hey (1989), Tectonics of the failing spreading system associated with the $95.5^{\circ} \mathrm{W}$ Galapagos propagator, J. Geophys. Res., 94(B10), 13,839-13,857, doi:10.1029/JB094iB10p13839.

Kleinrock, M., B. Tucholke, J. Lin, and M. Tivey (1997), Fast rift propagation at a slow-spreading ridge, Geology, 25, 639-642, doi:10.1130/00917613(1997)025<0639:FRPAAS $>2.3$.CO;2.

Kong, L., R. Detrick, P. Fox, L. Mayer, and W. Ryan (1988), The morphology and tectonics of the Mark area from Sea Beam and Sea MARC I observations (Mid-Atlantic Ridge $23^{\circ} \mathrm{N}$ ), Mar. Geophys. Res., 10, 59-90, doi:10.1007/BF02424661.

Kopp, H., C. Kopp, J. Phipps Morgan, E. Flueh, W. Weinrebe, and W. Morgan (2003), Fossil hot spot-ridge interaction in the Musicians Seamount Province: Geophysical investigations of hot spot volcanism at volcanic elongated ridges, J. Geophys. Res., 108(B3), 2160 doi:10.1029/2002JB002015

Krasnov, S., I. Poroshina, S. Cherkashev, E. Mikhalsky, and M. Maslov (1997), Morphotectonics, volcanism and hydrothermal activity on the East Pacific Rise between $21^{\circ} 12^{\prime} \mathrm{S}$ and $22^{\circ} 40^{\prime} \mathrm{S}$, Mar. Geophys. Res., 19, 287-317, doi:10.1023/A:1004237304068.

Kuo, B.-Y., and D. Forsyth (1988), Gravity anomalies of the ridge-transform system in the South Atlantic between 31 and $34.5^{\circ} \mathrm{S}$ : Upwelling centers and variations in crustal thickness, Mar. Geophys. Res., 10, 205-232, doi:10.1007/BF00310065
Lagabrielle, Y., D. Bideau, M. Cannat, J. Karson, and C. Mevel (1998), Ultramafic-mafic plutonic rock suites exposed along the Mid-Atlantic ridge $\left(10^{\circ} \mathrm{N}-30^{\circ} \mathrm{N}\right)$. Symmetrical-asymmetrical distribution and implications for seafloor spreading processes, in Faulting and Magmatism at Mid-Ocean Ridges, Geophys. Monogr. Ser., vol. 106, edited by W. Buck et al., pp. 153-176, AGU, Washington D. C.

Langmuir, C., J. Bender, and R. Batiza (1986), Petrological and tectonic segmentation of the East Pacific Rise, $5^{\circ} 30^{\prime}-14^{\circ} 30^{\prime} \mathrm{N}$, Nature, 322, 422-429, doi: $10.1038 / 322422 \mathrm{a} 0$

Lonsdale, P. (1983), Overlapping rift zones at the $5.5^{\circ} \mathrm{S}$ offset of the East Pacific Rise, J. Geophys. Res., 88(B11), 9393-9406, doi:10.1029/ JB088iB11p09393.

Lonsdale, P. (1985), Nontransform offsets of the Pacific-Cocos plate and their traces on the rise flank, Geol. Soc. Am. Bull., 96, 313-327, doi:10.1130/0016-7606(1985)96<313:NOOTPP >2.0.CO;2.

Lonsdale, P. (1986), Comments on "East Pacific Rise from Siqueiros to Orozco fracture zones: Along-strike continuity of axial neovolcanic zone and structure and evolution of overlapping spreading centers" by K. Macdonald, J. Sempere and P. Fox, J. Geophys. Res., 91(B10), 10,493-10,499, doi:10.1029/JB091iB10p10493.

Macdonald, K. (1998), Linkages between faulting, volcanism, hydrothermal activity and segmentation on fast spreading centres, in Faulting and Magmatism at Mid-Ocean Ridges, Geophys. Monogr. Ser., vol. 106 , edited by W. R. Buck et al., pp. 27-58, AGU, Washington, D. C.

Macdonald, K., and P. Fox (1983), Overlapping spreading centres: New accretion geometry on the East Pacific Rise, Nature, 302, 55-58, doi:10.1038/302055a0.

Macdonald, K., and P. Fox (1988), The axial summit graben and crosssectional shape of the East Pacific Rise as indicators of axial magma chambers and recent volcanic eruptions, Earth Planet. Sci. Lett., 88 , 119-131, doi:10.1016/0012-821X(88)90051-9

Macdonald, K. C., J.-C. Sempere, and P. Fox (1984), East Pacific Rise from Siqueiros to Orozco fracture zones: Along-strike continuity of axial neovolcanic zone and structure and evolution of overlapping spreading centers, J. Geophys. Res., 89(B7), 6049-6069, doi:10.1029/ JB089iB07p06049.

Macdonald, K., P. Fox, L. Perram, M. Eisen, R. Haymon, S. Miller, M. Carbotte, and A. Shor (1988), A new view of the mid-ocean ridge from the behaviour of ridge-axis discontinuities, Nature, 335, 217-225, doi:10.1038/335217a0.

Macdonald, K., D. Scheirer, and S. Carbotte (1991), Mid-ocean ridges: Discontinuities, segments and giant cracks, Science, 253, 986-994, doi:10.1126/science.253.5023.986.

Macdonald, K., et al. (1992), The East Pacific Rise and its flanks $8-18^{\circ} \mathrm{N}$ : History of segmentation, propagation and spreading direction based on SeaMarc II and Sea Beam studies, Mar. Geophys. Res., 14, 299-344, doi:10.1007/BF01203621.

Magde, L., C. Kincaid, D. Sparks, and R. Detrick (1996), Combined laboratory and numerical studies of the interaction between buoyant and plate-driven upwelling beneath segmented spreading centers, J. Geophys. Res., 101(B10), 22,107-22,122, doi:10.1029/96JB01910.

Mart, Y., and O. Dauteuil (2000), Analogue experiments of propagation of oblique rifts, Tectonophysics, 316, 121-132, doi:10.1016/S00401951(99)00231-0.

Mauduit, T., and O. Dauteuil (1996), Small-scale models of oceanic transform zones, J. Geophys. Res., 101(B9), 20,195-20,209, doi:10.1029/ 96JB01509.

McClain, J., and M. Wright (1990), The morphology and structure of the West O'Gorman Fracture Zone, Mar. Geophys. Res., 12, 317-328, doi:10.1007/BF02428201.

McKenzie, D. (1986), The geometry of propagating rifts, Earth Planet. Sci. Lett., 77, 176-186, doi:10.1016/0012-821X(86)90159-7.

Morgan, J., and E. Parmentier (1985), Causes and rate limiting mechanisms of ridge propagation: A fracture mechanics model, J. Geophys. Res., 90, 8603-8612, doi:10.1029/JB090iB10p08603.

Mutter, J., and J. Karson (1992), Structural processes at slow-spreading ridges, Science, 257, 627-634, doi:10.1126/science.257.5070.627.

Mutter, J., G. Barth, P. Buhl, R. Detrick, J. Orcutt, and A. Harding (1988), Magma distribution across ridge-axis discontinuities on the East Pacific Rise from multichannel seismic images, Nature, 336, 156-158, doi:10.1038/336156a0.

Naar, D., and R. Hey (1991), Tectonic evolution of the Easter microplate, J. Geophys. Res., 96(B5), 7961-7993, doi:10.1029/90JB02398.

Neves, M., R. Searle, and M. Bott (2003), Easter microplate dynamics, J. Geophys. Res., 108(B4), 2213, doi:10.1029/2001JB000908.

Okino, K., and K. Fujioka (2003), The Central Basin Spreading Center in the Philippine Sea: Structure of an extinct spreading center and implications for marginal basin formation, J. Geophys. Res., 108(B1), 2040 doi:10.1029/2001JB001095. 
Oldenburg, D., and J. Brune (1972), Ridge transform fault spreading pattern in freezing wax, Science, 178, 301-304, doi:10.1126/science. 178.4058.301.

Pardee, D., R. Hey, and F. Martinez (1998), Cross-sectional areas of midocean ridge axes bounding the Easter and Juan Fernandez microplates, Mar. Geophys. Res., 20, 517-531, doi:10.1023/A:1004768716893.

Perfit, M., and W. Chadwick (1998), Magmatism at mid-ocean ridges: Constrains from volcanological and geochemical investigations, in Faulting and Magmatism at Mid-Ocean Ridges, Geophys. Monogr. Ser., vol 106, edited by W. Buck et al., pp. 59-115, AGU, Washington, D. C.

Pollard, D., and A. Aydin (1984), Propagation and linkage of oceanic ridge segments, J. Geophys. Res., 89(B12), 10,017-10,028, doi:10.1029/ JB089iB12p10017.

Purdy, G., J.-C. Sempere, H. Schouten, D. Dubois, and R. Goldsmith (1990), Bathymetry of the Mid-Atlantic Ridge, $24^{\circ}-31^{\circ} \mathrm{N}$ : A map series, Mar. Geophys. Res., 12, 247-252, doi:10.1007/BF02428196.

Ramberg, H. (1981), Gravity, Deformation and the Earth's Crust, 2nd ed., 452 pp., Academic, London.

Ramsay, J., and M. Huber (1987), The Techniques of the Modern Structural Geology, vol. 1, Strain Analysis, 650 pp., Academic, London.

Ranalli, G. (1995), Rheology of the Earth, 2nd ed., 436 pp., Chapman and Hall, London.

Schouten, H., K. Klitgord, and J. Whitehead (1985), Segmentation of midocean ridges, Nature, 317, 225-229, doi:10.1038/317225a0.

Schouten, H., K. Klitgord, and D. Gallow (1993), Edge-driven microplate kinematics, J. Geophys. Res., 98(B4), 6689-6701, doi:10.1029/ 92JB02749.

Searle, R., R. Rusby, J. Engeln, R. Hey, J. Zukin, P. Hunter, T. LeBas, H. Hoffman, and R. Livermore (1989), Comprehensive sonar imaging of the Easter microplate, Nature, 341, 701-705, doi:10.1038/341701a0.

Segall, P., and D. Pollard (1983), Joint formation of granitic rock of the Sierra Nevada, Geol. Soc. Am. Bull., 94, 563-575, doi:10.1130/00167606(1983)94<563:JFIGRO>2.0.CO;2.

Sempere, J., and K. Macdonald (1986), Overlapping spreading centers: Implications from crack growth simulation by the displacement discontinuity method, Tectonics, 5, 151-163, doi:10.1029/TC005i001p00151.

Sempere, J., et al. (1997), The Southeast Indian Ridge between $88^{\circ} \mathrm{E}$ and $120^{\circ} \mathrm{E}$ : Variations in crustal accretion at constant spreading rate, $\mathrm{J}$. Geophys. Res., 102(B7), 15,489-15,505, doi:10.1029/97JB00171.

Severinghaus, J., and K. Macdonald (1988), High inside corners at ridgetransform intersections, Mar. Geophys. Res., 9, 353-367, doi:10.1007/ BF00315005.

Shah, A., M. Cormier, W. Ryan, W. Jin, J. Sinton, E. Bergmanis, J. Carlut, A. Bradley, and D. Yoerger (2003), Episodic dike swarms inferred from near-bottom magnetic anomaly maps at the southern East Pacific Rise, J. Geophys. Res., 108(B2), 2097, doi:10.1029/2001JB000564.

Shemenda, A., and A. Grocholsky (1991), A formation and evolution of overlapping spreading centers (constrained on the basis of physical modeling), Tectonophysics, 199, 389-404, doi:10.1016/00401951(91)90180-Z.
Shemenda, A., and A. Grocholsky (1994), Physical modeling of slow seafloor spreading, J. Geophys. Res., 99(B5), 9137-9153, doi:10.1029/ 93JB02995.

Sigmundsson, F. (2006), Plate tectonics: Magma does the splits, Nature, 442, 251-252, doi:10.1038/442251a.

Small, C. (1998), Global systematics of mid-ocean ridge morphology, in Faulting and Magmatism at Mid-Ocean Ridges, Geophys. Monogr. Ser. vol. 106, edited by W. Buck et al., pp. 1-25, AGU, Washington D. C.

Taylor, B., K. Crook, and J. Sinton (1994), Extensional transform zones and oblique spreading centers, J. Geophys. Res., 99(B10), 19,707-19,718, doi:10.1029/94JB01662.

Tentler, T. (2003a), Analogue modeling of tension fracture pattern in relation to mid-ocean ridge propagation, Geophys. Res. Lett., 30(6), 1268, doi:10.1029/2002GL015741.

Tentler, T. (2003b), Analogue modeling of overlapping spreading centers: Insights into their propagation and coalescence, Tectonophysics, 376 , 99-115, doi:10.1016/j.tecto.2003.08.011

Tentler, T. (2005), Propagation of brittle failure triggered by magma in Iceland, Tectonophysics, 406, 17-38, doi:10.1016/j.tecto.2005.05.016

Tentler, T. (2007), Focused and diffuse extension in controls of ocean ridge segmentation in analogue models, Tectonics, 26, TC5008, doi:10.1029/ 2006TC002038.

Tentler, T., and S. Mazzoli (2005), Architecture of normal faults in the rift zone of central north Iceland, J. Struct. Geol., 27, 1721-1739, doi:10.1016/j.jsg.2005.05.018.

Thibaud, R., O. Dauteuil, and P. Gente (1999), Faulting pattern along slowspreading ridge segments: A consequence of along-axis variation in lithospheric rheology, Tectonophysics, 312, 157-174, doi:10.1016/S00401951(99)00165-1.

Thomas, A., and D. Pollard (1993), The geometry of echelon fractures in rock: Implications from laboratory and numerical experiments, J. Struct. Geol., 15, 323-334, doi:10.1016/0191-8141(93)90129-X.

Tivey, M., H. Schouten, and M. Kleinrock (2003), A near-bottom magnetic survey of the Mid-Atlantic Ridge axis at $26^{\circ} \mathrm{N}$ : Implications for the tectonic evolution of the TAG segment, J. Geophys. Res., 108(B5), 2277, doi:10.1029/2002JB001967.

Wang, X., and J. Cochran (1993), Gravity anomalies, isostasy, and mantle flow at the East Pacific Rise crest, J. Geophys. Res., 98(B11), 19,50519,531, doi:10.1029/93JB01551.

Wilcock, W., S. Archer, and G. Purdy (2002), Microearthquakes on the Endeavour segment of the Juan de Fuca Ridge, J. Geophys. Res., 107(B12), 2336, doi:10.1029/2001JB000505

V. Acocella, Dipartimento Scienze Geologiche, Universitá Roma Tre, Largo S.L. Murialdo, 1, I-00146 Rome, Italy. (acocella@uniroma3.it)

T. Tentler, Department of Geology and Mineralogy, Royal Museum for Central Africa, Leuvensesteenweg 13, B-3080 Tervuren, Belgium. (tatiana_tentler@hotmail.com) 